\title{
SiNx Coatings Deposited by Reactive High Power Impulse Magnetron Sputtering: Process Parameters Influencing the Nitrogen Content
}

\author{
Susann Schmidt, Tuomas Hänninen, Cecilia Goyenola, Jonas Wissting, Jens Jensen, Lars \\ Hultman, Nico Goebbels, Markus Tobler and Hans Högberg
}

\section{Journal Article}

\section{Tweet}

N.B.: When citing this work, cite the original article.

Original Publication:

Susann Schmidt, Tuomas Hänninen, Cecilia Goyenola, Jonas Wissting, Jens Jensen, Lars Hultman, Nico Goebbels, Markus Tobler and Hans Högberg, SiNx Coatings Deposited by Reactive High Power Impulse Magnetron Sputtering: Process Parameters Influencing the Nitrogen Content, ACS Applied Materials and Interfaces, 2016. 8(31), pp.20386-20396.

http://dx.doi.org/10.1021/acsami.6b05830

Copyright: American Chemical Society

http://pubs.acs.org/

Postprint available at: Linköping University Electronic Press

http://urn.kb.se/resolve?urn=urn:nbn:se:liu:diva-131907

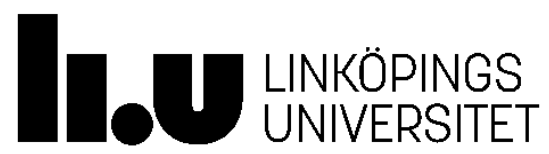




\title{
SiN $N_{x}$ Coatings Deposited by Reactive High Power Impulse Magnetron Sputtering:
}

\section{Process Parameters influencing the Nitrogen Content}

Susann Schmidt ${ }^{1) * *}$, Tuomas Hänninen ${ }^{1)}$, Cecilia Goyenola ${ }^{1)}$, Jonas Wissting ${ }^{1)}$, Jens Jensen ${ }^{1)}$, Lars Hultman ${ }^{1)}$, Nico Goebbels²), Markus Tobler²), and Hans Högberg ${ }^{1)}$

${ }^{1)}$ Thin Film Physics Div., Department of Physics (IFM), Linköping University, SE-581 83 Linköping, Sweden

2) IHI Ionbond AG, Industriestraße 211, CH-4600 Olten, Switzerland

\begin{abstract}
Reactive high power impulse magnetron sputtering (rHiPIMS) was used to deposit silicon nitride $\left(\mathrm{SiN}_{\mathrm{x}}\right)$ coatings for bio-medical applications. The $\mathrm{SiN}_{\mathrm{x}}$ growth and plasma characterization were conducted in an industrial coater, using Si targets and $\mathrm{N}_{2}$ as reactive gas. The effects of different $\mathrm{N}_{2}$-toAr flow ratios between 0 and 0.3 , pulse frequencies, target power settings and substrate temperatures on the discharge and the $\mathrm{N}$ content of $\mathrm{SiN}_{\mathrm{x}}$ coatings were investigated. Plasma ion mass spectrometry shows high amounts of ionized isotopes during the initial part of the pulse for discharges with low $\mathrm{N}_{2}$ to-Ar flow ratios of $<0.16$, while signals from ionized molecules rise with the $\mathrm{N}_{2}$-to-Ar flow ratio at the pulse end and during pulse-off times. Langmuir probe measurements show electron temperatures between 2 - $3 \mathrm{eV}$ for non-reactive discharges and 5.0 to $6.6 \mathrm{eV}$ for discharges in transition mode. The $\mathrm{SiN}_{\mathrm{x}}$ coatings were characterized with respect to their composition, chemical bond structure, density and mechanical properties by X-ray photoelectron spectroscopy, X-ray reflectivity, X-ray diffraction, and nanoindentation, respectively. The $\mathrm{SiN}_{\mathrm{x}}$ deposition processes and coating properties are mainly influenced by the $\mathrm{N}_{2}$-to-Ar flow ratio and thus by the $\mathrm{N}$ content in the $\mathrm{SiN}_{\mathrm{x}}$ films and to a lower extent by the HiPIMS frequencies and power settings as well as substrate temperatures. Increasing $\mathrm{N}_{2}$-to-Ar flow ratios lead to decreasing growth rates, while the $\mathrm{N}$ contents, coating densities, residual stresses and the hardnesses increase. These experimental findings were corroborated by density functional theory calculations of precursor species present during rHiPIMS.
\end{abstract}

Keywords: $\mathrm{SiN}_{\mathrm{x}}$, HiPIMS, positive ion plasma mass spectrometry, Langmuir probe measurements, residual film stress, XPS

*corresponding author:

Tel.: +4613288 974; fax: +4613137568

E-mail address: sussc@ifm.liu.se (S. Schmidt) 


\section{Introduction}

$\mathrm{SiN}_{\mathrm{x}}$ is a prospective coating material for metal joint replacements ${ }^{1-5}$; it is a biocompatible compound ${ }^{6}$ with a comparatively high hardness as well as wear resistance. Potential $\mathrm{SiN}_{\mathrm{x}}$ wear debris dissolves slowly in aqueous solution ${ }^{7-8}$. A recent study shows also that the dissolution rate can be tailored with the $\mathrm{N}$ content of the $\mathrm{SiN}_{\mathrm{x}}$ coating ${ }^{9}$. Additionally, $\mathrm{SiN}_{\mathrm{x}}$ coatings can prevent metal ion release from the metal bulk.

Silicon nitride $\left(\mathrm{SiN}_{\mathrm{x}}\right)$ thin films are commonly deposited by low pressure chemical vapor deposition and plasma enhanced chemical vapor deposition at deposition temperatures above $700{ }^{\circ} \mathrm{C}$ and $200{ }^{\circ} \mathrm{C}$, respectively. Both deposition techniques utilize commonly $\mathrm{SiH}_{4} / \mathrm{NH}_{3}, \mathrm{SiH}_{4} / \mathrm{N}_{2}$ or $\mathrm{SiCl}_{2} \mathrm{H}_{2} / \mathrm{NH}_{3}$ precursor combinations for the formation of $\mathrm{SiN}_{\mathrm{x}}{ }^{10-12}$. Such $\mathrm{H}$-rich precursors, together with comparatively low substrate temperatures, result in $\mathrm{H}$ contents as high as 30 at.\% in the $\mathrm{SiN}_{\mathrm{x}}$ coatings. This leads to a degradation of the favorable mechanical properties ${ }^{12-13}$. However, the application of $\mathrm{SiN}_{\mathrm{x}}$ as protective coating on metal joint replacements requires an excellent wear resistance and comparatively low growth temperatures $<450{ }^{\circ} \mathrm{C}$, since metal replacements degrade potentially under higher temperature loads.

An alternative to above mentioned limitations is the growth of $\mathrm{SiN}_{\mathrm{x}}$ by magnetron sputtering as it allows coating deposition without additional substrate heating. Here, $\mathrm{SiN}_{\mathrm{x}}$ films can be either deposited from a $\mathrm{Si}_{3} \mathrm{~N}_{4}$ compound target ${ }^{14}$, by reactive magnetron sputtering using $\mathrm{N}_{2}$ as $\mathrm{N}$-source ${ }^{15-16}$, or a combination of both ${ }^{17}$. One of the major growth parameters for the deposition of $\operatorname{SiN}_{\mathrm{x}}$ by reactive magnetron sputtering is the amount of $\mathrm{N}_{2}$ supplied to the glow discharge as it determines the deposition process characteristics ${ }^{18}$ as well as the $\mathrm{N}$ content in the $\mathrm{SiN}_{\mathrm{x}}$ coatings. In studies ${ }^{15-16,19} \mathrm{SiN}_{\mathrm{x}}$ thin films were deposited by reactive radio frequency magnetron sputtering. Here, the researchers found reduced $\mathrm{N}$ contents in the $\operatorname{SiN}_{x}$ films with increasing reactive gas flow. This was attributed to an insufficient activation of $\mathrm{N}_{2}$, caused by a decreasing amount of electrons as the $\mathrm{N}_{2}$-to-Ar flow ratio $\left(\boldsymbol{f}_{\boldsymbol{N}_{2} / A r}\right)$ increased. The lowered $\mathrm{N}$ contents resulted also in a decreased hardness and residual stresses.

$\mathrm{SiN}_{\mathrm{x}}$ can also be synthesized by reactive high power impulse magnetron sputtering (rHiPIMS) in $\mathrm{Ar} / \mathrm{N}_{2}$ atmosphere ${ }^{3-4,20}$. The inherent, comparatively high plasma densities in HiPIMS ${ }^{9,21-23}$ should yield sufficient $\mathrm{N}_{2}$ activation even at elevated $\mathrm{N}_{2}$-flows. However, corresponding publications that were issued so far concentrate to our best knowledge mainly on coating properties. Hence, there is a need to investigate HiPIMS deposition parameters for the growth of $\operatorname{SiN}_{\mathrm{x}}$ and correlate those to resulting $\mathrm{SiN}_{\mathrm{x}}$ properties.

In this study, we report about the influence of rHiPIMS deposition parameters on the $\mathrm{N}$ content of $\mathrm{SiN}_{\mathrm{x}}$ coatings. Specifically, the $\boldsymbol{f}_{\boldsymbol{N}_{\mathbf{2}} / \mathbf{A r}}$, target power settings, and the substrate temperature were considered. Reactive Si/Ar/ $/ \mathrm{N}_{2}$ HiPIMS discharges were studied using plasma ion mass spectrometry and Langmuir probe measurements. The effect of above mentioned deposition parameters on the coating composition, density, residual stresses and hardness were investigated by X-ray photoelectron spectroscopy (XPS), $\mathrm{X}$-ray reflectivity (XRR), X-ray diffraction (XRD) and nanoindentation, respectively. 


\section{Materials and Methods}

Density functional theory calculations within the synthetic growth concept approach ${ }^{24}$ were performed to model the most abundant precursor species in $\mathrm{Si} / \mathrm{N}_{2}$ discharges, as corroborated herein by plasma mass spectrometry. The study involved geometry optimizations and cohesive energy calculations of the following neutral species: $\mathrm{Si}, \mathrm{N}, \mathrm{N}_{2}, \mathrm{Si}_{2}$, and $\mathrm{SiN}$. The cohesive energy per atom $\left(E_{\text {coh/at }}\right)$ is defined as the required energy for splitting the considered system into isolated atomic species normalized by the total number of atoms, and is calculated according to equation 1 :

$$
E_{c o h / a t}=-\frac{E_{s y s t e m}-N_{N} \times E_{N}-N_{S i} \times E_{S i}}{N_{N}+N_{S i}}
$$

, where $E_{\text {system }}$ is the total energy of the model system, $N_{N}$ and $N_{S i}$ are the number of $\mathrm{N}$ and Si atoms, and $E_{N}$ and $E_{S i}$ are the energies of the corresponding free atoms in the ground state, respectively. The calculations were performed at the level of the generalized gradient approximation as implemented in the program Gaussian $09{ }^{25}$. The results reported herein were obtained using the PW91 ${ }^{26}$ exchange and correlation functionals with the $6-31 \mathrm{G}^{* *}$ basis set augmented with polarization functions.

The deposition of $\mathrm{SiN}_{\mathrm{x}}$ coatings and plasma characterization were conducted in the industrial coating unit CC800/9 ML (CemeCon AG, Germany) at Linköping University, for which two out of six cathodes can be operated in HiPIMS mode. A base pressure of $<1 \mathrm{mPa}$ was achieved prior to deposition. Si targets with a purity of $99.8 \%$ and $\mathrm{N}_{2}$-to-Ar flow ratios $\left(f_{N_{2} / A r}\right)$ ranging between 0 and 0.31 were used for the deposition of $\operatorname{SiN}_{\mathrm{x}}$. The $f_{N_{2} / A r}$ (Eq. 2) is defined as

$$
f_{N_{2} / A r}=\frac{f_{N_{2}}}{f_{A r}}
$$

where $f_{N_{2}}$ and $f_{A r}$ are the $\mathrm{N}_{2}$ and Ar gas flows, respectively. The deposition pressure was kept constant at $400 \mathrm{mPa}$. $\mathrm{SiN}_{\mathrm{x}}$ films were deposited onto conventional p-doped $\mathrm{Si}(001)$ wafers to thicknesses ranging between $1900 \mathrm{~nm}$ and $2500 \mathrm{~nm}$. In all HiPIMS processes pulse widths of $200 \mu$ s and a pulsed bias voltage $\left(\mathrm{U}_{\mathrm{B}}\right)$ of $-100 \mathrm{~V}$, synchronized to the cathode pulses, were used. The pulse frequency, average target power and the substrate temperature $\left(T_{s}\right)$ were varied between $0.2 \mathrm{kHz}$ and $1 \mathrm{kHz}, 600 \mathrm{~W}$ and $4000 \mathrm{~W}$, as well as $190^{\circ} \mathrm{C}$ and $530^{\circ} \mathrm{C}$, respectively.

Time-averaged and time-resolved plasma mass spectrometry were conducted with a Hiden EQP 1000 unit in order to access the composition and temporal evolution of non-reactive and reactive Si discharges. First, the most abundant plasma species were determined with mass scans from 0 to $100 \mathrm{amu}$ at an ion energy of $0.6 \mathrm{eV}$. Subsequently, the ion energy distribution functions (IEDFs) of the most abundant positive ions were recorded. Time-averaged data were acquired using a distance of 60 $\mathrm{mm}$ between the mass spectrometers orifice and the target surface, where the orifice had an opening of $50 \mu \mathrm{m}$. For the acquisition of time-resolved data, the orifice faced the target with a distance of $320 \mathrm{~mm}$ and had an opening of $300 \mu \mathrm{m}$. Here, time-resolved IEDFs of the isotopes ${ }^{15} \mathrm{~N},{ }^{29} \mathrm{Si}$, ${ }^{30} \mathrm{Si}$, and ${ }^{36} \mathrm{Ar}$ were recorded, due to the similarity of the masses and the abundance of $\mathrm{Si}$ and $\mathrm{N}$ ions. For all measurements, ion energies were recorded between $-0.4 \mathrm{eV}$ and $30 \mathrm{eV}$ with a resolution of $0.5 \mathrm{eV}$ and the spectrometer dwell time was set so that the presented data represent an average of at least 30 HiPIMS pulses. Time- 
resolved ion mass spectrometry measurements were triggered at pulse onset of the target voltage signal by a Tektronix DPO4054 digital oscilloscope. The delay time for the measurements, relative to the onset of the HiPIMS pulse, ranged from $40 \mu$ s up to $600 \mu$ s with an increment of $20 \mu \mathrm{s}$. For the presented time-resolved data the ion time-of-flight (TOF) within the mass spectrometer was corrected, thus data represent the plasma characteristics at the spectrometer orifice. TOF-correction was applied according to Bohlmark et al. ${ }^{27}$. A mean particle energy of $2 \mathrm{eV}$ was used for all TOF calculations. The low particle energies are due to the high distance between the target and spectrometer orifice. During ion mass spectrometry measurements the target current and target voltage waveforms were recorded with a Tektronix DPO4054 digital oscilloscope.

A custom-made Langmuir probe set-up was used for time-resolved measurements of the electron temperature $\left(\mathrm{T}_{\mathrm{e}}\right)$. A tungsten wire with a diameter of $350 \mu \mathrm{m}$ was insulated by a ceramic tube, except for $4 \mathrm{~mm}$ that were exposed to the plasma. A transconductance amplifier was used to drive a current trough the probe. The voltage compliance for the amplifier was $-90 \mathrm{~V}$ to $+30 \mathrm{~V}$ and its parasitic output capacitance was measured to be $\sim 200$ pF. An Agilent DSO-X 2002 oscilloscope was used to measure the voltage on the probe for each set current, yielding a resolution of $0.78 \mathrm{~V}$. The oscilloscope measurements were averaged over 32 waveforms. For the measurements, a substrate temperature of 350 ${ }^{\circ} \mathrm{C}$ was used. The electron temperature of HiPIMS processes was extracted for pulse times corresponding to the peak target current.

Cross-sectional scanning electron microscopy (SEM, LEO 1550 Gemini, Zeiss, Germany) was used to determine the $\mathrm{SiN}_{\mathrm{x}}$ film thickness and hence the growth rate. The instrument, equipped with an in-lens detector, was operated at an acceleration voltage of $3 \mathrm{kV}$ at a working distance of $\sim 3 \mathrm{~mm}$.

The chemical composition and bonding states of $\mathrm{SiN}_{\mathrm{x}}$ coatings were investigated by XPS (Axis UltraDLD, Kratos Analytical, Manchester, UK) using monochromatic $\mathrm{Al}\left(\mathrm{K}_{\alpha}\right) \mathrm{X}$-ray radiation $(h v=1486.6 \mathrm{eV})$. The base pressure in the analysis chamber during acquisition was $<1 \times 10^{-7} \mathrm{~Pa}$. XPS core level spectra of the Si2p, Ar2p, N1s, C1s, and O1s regions were recorded on as-received samples and after sputter cleaning for $120 \mathrm{~s}$ with a $2 \mathrm{keV} \mathrm{Ar}^{+}$ion beam, rastered over an area of $3 \times 3 \mathrm{~mm}^{2}$ at an incidence angle of $70^{\circ}$ with respect to the surface normal. Automatic charge compensation was applied throughout the acquisition, owing to the electrical insulating nature of the $\mathrm{SiN}_{\mathrm{x}}$ films as their $\mathrm{N}$ content increases. After subtraction of a Shirley-type background from core level spectra obtained after $\mathrm{Ar}^{+}$ sputter cleaning, the chemical composition of the $\mathrm{SiN}_{\mathrm{x}}$ films was extracted, using elemental cross sections provided by Kratos Analytical. Core level spectra obtained from sputter cleaned samples were also used to study the bond structure of the $\mathrm{SiN}_{\mathrm{x}}$ films. Here, a Shirley-type background was subtracted and the core level spectra were referenced to the C-C/C-CH bond at $285 \mathrm{eV}^{28}$. The spectra were fitted using a Voigt peak shape with a Lorentzian contribution of $30 \%$. The full width at half maximum (FWHM) of all components was restricted to $<2 \mathrm{eV}$.

XRD $\Theta-2 \Theta$ scans were used to investigate whether the coatings show crystalline phases. The $\Theta-2 \Theta$ scans were recorded with a Philips powder diffractometer (PW 1820) equipped with a $\mathrm{Cu}(\mathrm{K} \alpha)$ radiation source operated at $40 \mathrm{kV}$ and $40 \mathrm{~mA}$. 
The residual stresses in the films were determined from the wafer curvature, assessed by XRD (PANalytical Empyrean) ${ }^{29}$. The diffractometer, equipped with a $\mathrm{Cu} \mathrm{K} \alpha_{1}$ source, was operated at $45 \mathrm{kV}$ and $40 \mathrm{~mA}$. The Stoney formula for anisotropic single crystal Si (001) was used to relate the measured substrate curvature to the residual coating stress, assuming uniform plane stress in the film ${ }^{30}$. The same instrument was used to investigate the film density by XRR. The density was evaluated using the PANalytical X'Pert reflectivity software. Here, a 3-layer model, resembling the substrate, the SiN $_{\mathrm{x}}$ films and a surface oxide layer was applied.

The hardness and elastic modulus of the $\mathrm{SiN}_{\mathrm{x}}$ films were measured in a CSIRO UMIS nanoindenter (Fischer-Cripps Laboratories, New South Wales, Australia) equipped with three-sided Berkovich tip. All films were tested in load-controlled mode. For the tests, 30 indents of increasing loads between $1 \mathrm{mN}$ and $15 \mathrm{mN}$ were performed. The method suggested by Oliver and Pharr ${ }^{31}$ was applied for evaluation. 


\section{Results and Discussion}

\subsection{Theoretical calculations}

In order to determine the role of the precursor species that are active during the HiPIMS deposition of $\mathrm{SiN}_{\mathrm{x}}$ films, the species were evaluated by their stability, and number of dangling bonds. Table 1 shows the $E_{c o h / a t}$, and bond lengths for the diatomic species, as well as the possible plasma reactions in which they are involved. Our calculations show that the $\mathrm{Si} / \mathrm{Ar} / \mathrm{N}_{2}$ plasma is dominated by $\mathrm{N}_{2}, \mathrm{~N}, \mathrm{Si}, \mathrm{SiN}$, and $\mathrm{Si}_{2}$. These precursor species are created by either dissociation or recombination reactions in the plasma or at the target surface. The values obtained for bond lengths and reaction enthalpies are in agreement with the literature ${ }^{32}$. The two species with a distinguished role in film formation are the dimers $\mathrm{SiN}$ and $\mathrm{Si}_{2}$, as these form effortlessly, are rather unstable (low $E_{\text {coh/at }}$ ) and are chemically very reactive due to a comparatively high amount of dangling bonds. Regarding the reactive gas molecular nitrogen, its main role is to provide monatomic nitrogen to the sputtering process, but has little impact on the film formation process.

Table 1: $E_{\text {coh/at }}$, bond lengths, possible reactions and corresponding calculated reaction enthalpies for the diatomic precursor species: $\mathrm{N}_{2}$, SiN, and $\mathrm{Si}_{2}$.

\begin{tabular}{ccccc}
\hline Precursor species & $\mathrm{E}_{\text {coh/at }}(\mathrm{eV} / \mathrm{at})$ & Bond length $(\AA)$ & Reactions & $\Delta \mathrm{H}(\mathrm{eV})$ \\
\hline \multirow{2}{*}{$\mathrm{N}_{2}$} & \multirow{2}{*}{-5.15} & 1.12 & $\mathrm{~N}_{2} \rightarrow 2 \mathrm{~N}$ & 10.2 \\
\cline { 3 - 5 } & & & $2 \mathrm{~N} \rightarrow \mathrm{N}_{2}$ & -10.2 \\
\hline $\mathrm{SiN}$ & -2.48 & 1.59 & $\mathrm{Si}+\mathrm{N} \rightarrow \mathrm{SiN}$ & -4.9 \\
\hline $\mathrm{Si}_{2}$ & -1.68 & 2.18 & $2 \mathrm{Si} \rightarrow \mathrm{Si}_{2}$ & -3.4 \\
\hline
\end{tabular}

\subsection{Process Characteristics and Plasma Characterization}

The target current and target voltage waveforms as a function of the pulse time for discharges using different $f_{N_{2} / A r}$ and pulse energies $\left(\mathrm{E}_{\mathrm{pP}}\right)$ are shown in figures $1 \mathrm{a}$ ) and $\mathrm{b}$ ). Current and voltage waveforms were recorded using a pulse frequency of $0.3 \mathrm{kHz}$ and an average target power of $3000 \mathrm{~W}, 2000 \mathrm{~W}$ and $1000 \mathrm{~W}$, corresponding to pulse energies in non-reactive processes of $10 \mathrm{Ws}, 6.7 \mathrm{Ws}$, and $3.4 \mathrm{Ws}$, respectively. Increasing the $\mathrm{E}_{\mathrm{p} p}$ results in rising peak target currents and decreasing voltages, and hence in increasingly dynamic discharges. The target current and voltage waveforms are similar for the nonreactive discharges and discharges conducted in $f_{N_{2} / A r}=0.16$. For the discharges using a $f_{N_{2} / A r}=0.30$, a slight increase of the peak target current and target voltage is observed. The target current decreases drastically as $f_{N_{2} / A r}$ is further increased to 0.50 , while the target voltage increases. The discharge at $f_{N_{2} / A r}$ of 0.50 was only possible for a comparatively high pulse energy of $10 \mathrm{Ws}$.

The target current reflects in first approximation the number of charged species in the vicinity of the target, where the amount of generated ions and the secondary electron emission contribute. The secondary electron emission yield $\left(\gamma_{\mathrm{SE}}\right)$ is influenced by the ionization energy of the working gas $\left(\mathrm{I}_{\mathrm{p}}\right)$ and the work function $(\varphi)$ of the target surface ${ }^{33}$. Upon introduction of $\mathrm{N}_{2}$ to the Si-discharge, the 
effective $\mathrm{I}_{\mathrm{p}}$ of the process gas does not change considerably owing to similar ionization energies of $\mathrm{N}_{2}$ $\left(\mathrm{I}_{\mathrm{P}}\left(\mathrm{N}_{2}\right)=15.6 \mathrm{eV}\right)$ and $\mathrm{N}\left(\mathrm{I}_{\mathrm{P}}(\mathrm{N})=14.53 \mathrm{eV}\right)$ and $\mathrm{Ar}\left(\mathrm{I}_{\mathrm{P}}(\mathrm{Ar})=15.75 \mathrm{eV}\right)$. Thus, $\gamma_{\mathrm{SE}}$ is not significantly influenced by $\mathrm{I}_{\mathrm{p}}$ of the process gas. Additionally, the target surface chemistry becomes altered by the addition of $\mathrm{N}_{2}$ and an increase of the target surface work function from $4.83 \mathrm{eV}^{34}$ for a pure Si surface to $\sim 7 \mathrm{eV}^{35}$ estimated for the $\mathrm{N}$ terminated Si target surface leads to decreased $\gamma_{\mathrm{SE}}$. In consequence, decreasing the peak target currents may be observed. However, this is first observed at a comparatively high $f_{N_{2} / A r}$ of 0.50 . Therefore, rather than $\gamma_{\mathrm{SE}}$, the generation of ions in the vicinity of the target and the sputter yield of a compound target surface influence the $\mathrm{Si} / \mathrm{N}_{2}$ discharge characteristics to a greater extent.

The slightly higher peak target currents obtained at $f_{N_{2} / A r}$ of 0.30 are attributed to the dissociation of $\mathrm{N}_{2}$. Here, the target surface chemistry may on average not be significantly affected; Upon $\mathrm{N}_{2}$ incorporation, dangling $\mathrm{Si}$ bonds at the target surface get terminated by $\mathrm{N}_{2}$ or $\mathrm{N}$ during comparatively long pulse-off times. This leads to a partially developed SiN layer at the target surface, which is sputtered away during pulse-on times and the target is operated in transition mode. At a deposition pressure of $400 \mathrm{mPa}$ the transition mode is observed at a $f_{N_{2} / A r}$ of 0.30 . As $f_{N_{2} / A r}$ is increased to 0.50 , the target current and voltage waveforms suggest that a permanent SiN compound layer is formed at the target surface and is not sputtered away during pulse-on times. Here, the discharge is operated in poisoned mode. The reduction of the peak target current is mainly caused by a reduced sputter yield of the SiN target surface compound, and to minor extents by a lowered $\gamma_{\mathrm{SE}}$.

The voltage waveforms diverge increasingly as the $f_{N_{2} / A r}$ increase and the pulse energies are decreased. At a low $\mathrm{E}_{\mathrm{pP}}$ of $3.4 \mathrm{Ws}$, rising $f_{\mathrm{N}_{2} / \mathrm{Ar}}$ result in the largest drop of the target voltage. This is attributed to a decreased sputter yield of the target material at comparatively low target voltages. Hence, the $\mathrm{N}$ removal from the target surface is less efficient. Comparing the bond strength of Si-Si and Si-N of $\sim 2.30 \mathrm{eV}$ and $\sim 3.68 \mathrm{eV}$, respectively, it is apparent that approximately $40 \%$ more energy needs to be invested in the reactive sputter process to initiate knock out events at the target surface. Thus, increasing the average discharge power or $\mathrm{E}_{\mathrm{pP}}$ delays the onset of target poisoning. This is illustrated in figure $1 \mathrm{~b}$ ), where the target voltage waveform does not show significant changes with increasing $f_{N_{2} / A r}$ at $\mathrm{E}_{\mathrm{pP}}=10 \mathrm{Ws}$. It is also in agreement with the fact that the discharge in poisoned mode using $f_{\mathrm{N}_{2} / \mathrm{Ar}}=$ 0.50 was only possible for a comparatively high pulse energy of 10 Ws. Finally, the results from current and voltage waveforms are in agreement with findings reported by Depla et al. ${ }^{36}$. 


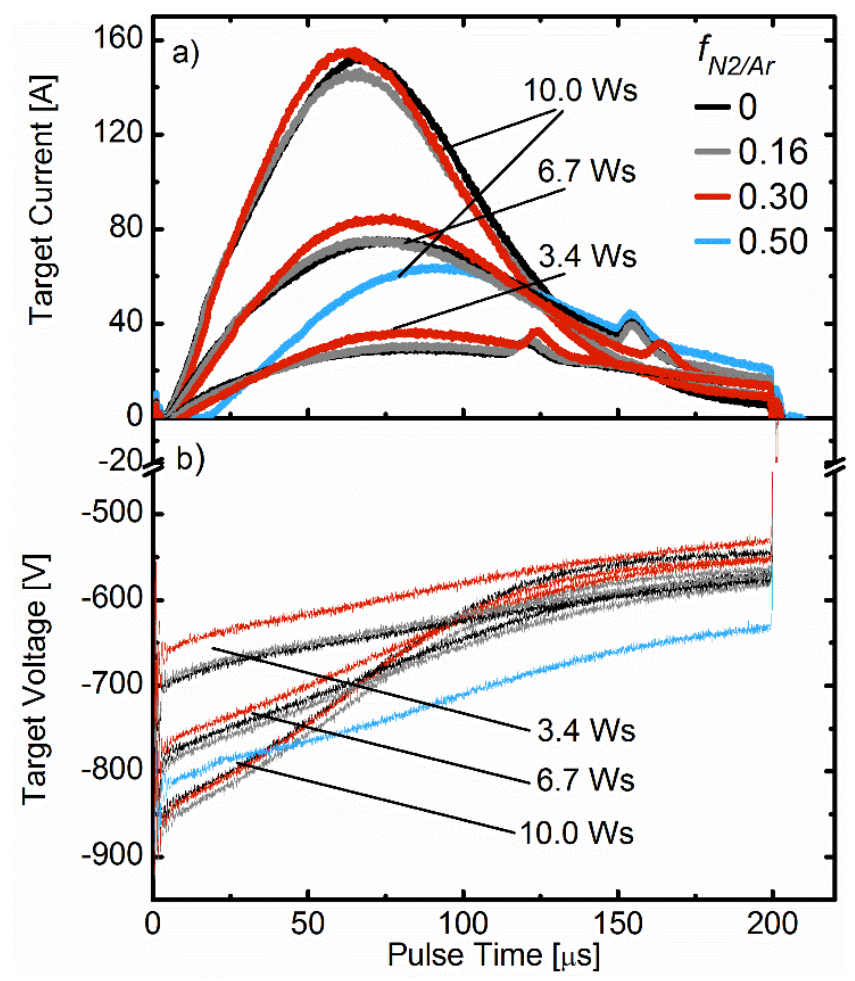

Figure 1 a) and b): Target current a), and target voltage b) over the pulse time recorded for processes using a pulse frequency of $0.3 \mathrm{kHz}$ and an average target power of $3000 \mathrm{~W}, 2000 \mathrm{~W}$ and $1000 \mathrm{~W}$ corresponding to pulse energies in non-reactive processes of $10 \mathrm{Ws}, 6.7 \mathrm{Ws}$, and $3.4 \mathrm{Ws}$, respectively and different $\mathrm{N}_{2}$-to-Ar flow ratios $\left(f_{N 2 / A r}\right)$. The discharge using $f_{N 2 / A r}=0.50$ was only feasible at $10 \mathrm{Ws}$.

Figure 2 a) - c) shows IEDFs recorded for most prevalent plasma species of discharges with different $f_{N_{2} / A r}$ using a pulse frequency of $0.3 \mathrm{kHz}$ and an average target power of $1000 \mathrm{~W}$, corresponding to an $\mathrm{E}_{\mathrm{pP}}$ of 3.4 Ws. As shown in figure $2 \mathrm{a}$ ) - c), the addition of $\mathrm{N}_{2}$ to the sputter gas results in a strong reduction of the ion flux and energy for all precursor fragments. Reduced ion energies and fluxes are already recorded at $f_{N_{2} / A r}=0.16$ (cf. figure $2 \mathrm{~b}$ )). The shape of the IEDF assigned to $\mathrm{Si}^{+}$or $\mathrm{N}_{2}{ }^{+}$in figure $2 \mathrm{~b}$ ) resembles the shape of $\mathrm{Si}^{+}$recorded for the non-reactive discharge, but shows a reduced count rate for ions with energies ranging between 15 and $22 \mathrm{eV}$. Moreover, low energy ions that were recorded between $5 \mathrm{eV}$ and $10 \mathrm{eV}$ in the non-reactive discharge shift towards lower energies by approximately 5 $\mathrm{eV}$. The variations observed in the corresponding $\mathrm{Si}^{+} / \mathrm{N}_{2}{ }^{+}$IEDF are ascribed to be mainly due to the combination of IEDFs arising from $\mathrm{N}_{2}{ }^{+}$and $\mathrm{Si}^{+}$. Thus, the $\mathrm{Si}^{+} / \mathrm{N}_{2}{ }^{+}$IEDF is a combination of IEDFs from ions originating from the target $\left(\mathrm{Si}^{+}\right)$and from the plasma $\left(\mathrm{N}_{2}{ }^{+}\right)$. In a similar experimental set-up and for $\mathrm{C}$ discharges, $\mathrm{N}_{2}{ }^{+}$was shown to originate in the plasma bulk rather than from the target ${ }^{37}$. In ${ }^{37}$ the corresponding $\mathrm{N}_{2}{ }^{+}$IEDFs were mainly composed of low energetic and thermalized ions and did not resemble the shape of ions originating from the target, while IEDFs from $\mathrm{N}^{+}$resembled the shape of the target ions. Hence, it was concluded that $\mathrm{N}^{+}$is originating from the target. The latter is to some extend also observed for the here investigated discharges as the IEDF assigned to $\mathrm{N}^{+}$(and $\mathrm{Si}^{2+}$ ) in figure $2 \mathrm{~b}$ ) shows a comparatively high count rate for ions with energies ranging between $15 \mathrm{eV}$ and $20 \mathrm{eV}$. However, this IDEF shows also high amounts of thermalized ions, which may arise from the plasma. 
The contribution of $\mathrm{Si}^{2+}$ to this IEDF is expected to be negligible, due to the fact that no $\mathrm{Si}^{2+}$ was found in the corresponding non-reactive discharges and the comparatively high second ionization energy of $\mathrm{Si}$ $\left(I_{P}^{S i^{2+}}=16.35 \mathrm{eV}\right)$. As in the case of the discharge in pure Ar, the reactive discharge contains high amounts of $\mathrm{Ar}^{2+}$, which even exceeds that of $\mathrm{Ar}^{+}$at a $f_{N_{2} / A r}=0.16$. As more $\mathrm{N}_{2}$ is added to the working gas, all IEDFs show reduced count rates and energies. This is attributed to a N-terminated target surface and a lowered sputter yield of the Si-N compound (cf. $\mathrm{E}_{\text {coh/at }}$ in table 1, and figure 1) as well as to the ability of $\mathrm{N}_{2}$ to cool the plasma efficiently. The results from time averaged ion mass spectrometry are in agreement with results and conclusions drawn from current and voltage waveforms and reflect our theoretical calculations (cf. 3.1 Theoretical calculations).

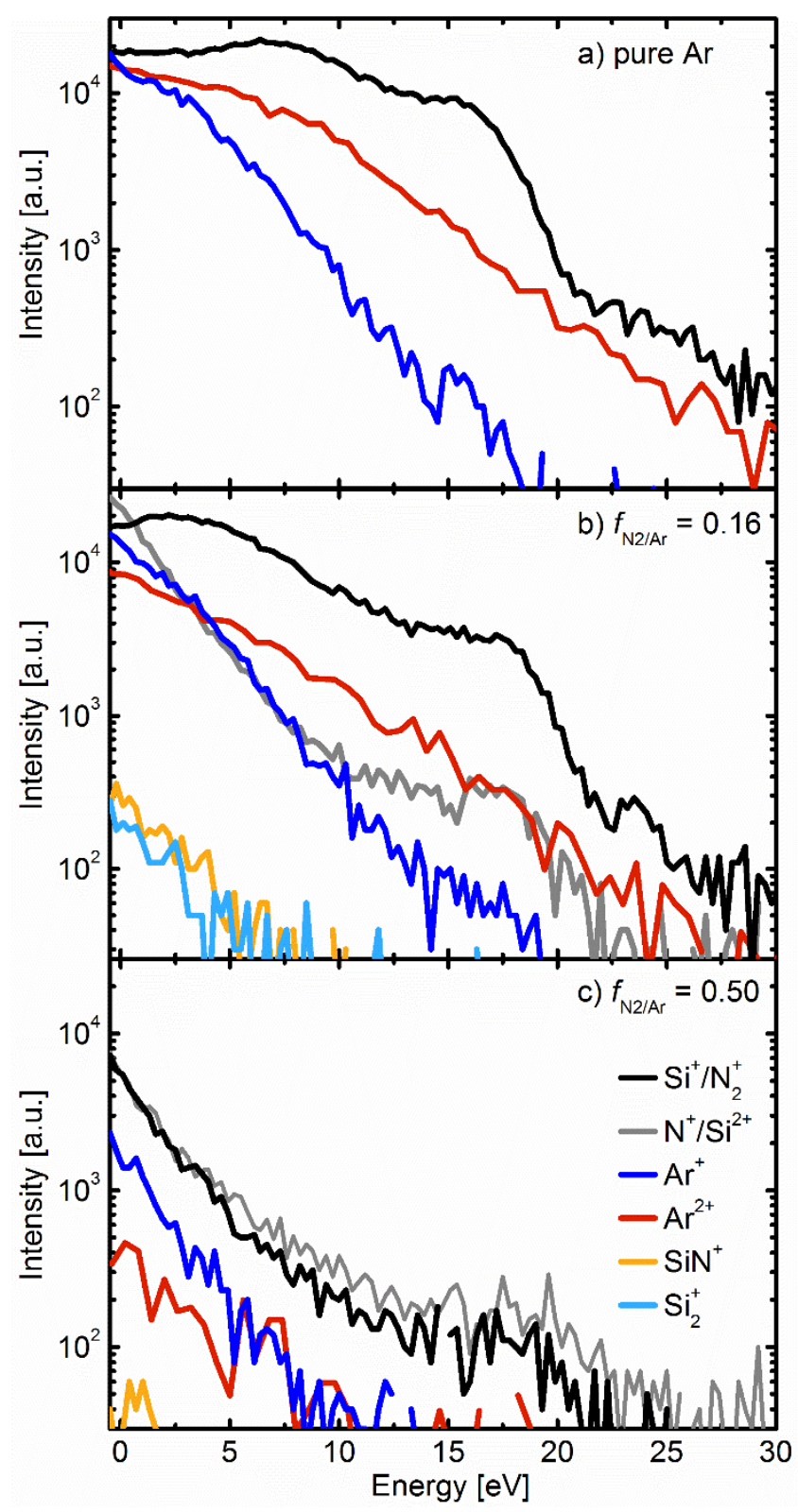

Figure 2 a)-c): IEDFs of $\mathrm{Si} / \mathrm{Ar} / \mathrm{N}_{2}$ discharges using a deposition pressure of $400 \mathrm{mPa}$, a pulse frequency of 0.3 $\mathrm{kHz}$ and an average target power of $1000 \mathrm{~W}$; a) in pure $\mathrm{Ar}, \mathrm{b}) f_{N 2 / A r}=0.16$, and c) $f_{N 2 / A r}=0.50$. 
Langmuir probe measurements were carried out for discharges using $0.3 \mathrm{kHz}$ in pure $\mathrm{Ar}$, as well as in gas mixtures with $f_{N_{2} / A r}$ of 0.16 and 0.28 . The electron temperature, shown in figure 3 , was extracted at a pulse time of $60 \mu \mathrm{s}$, representing the point at which the target current reaches its maximum value (cf. figure $1 \mathrm{a}$ )). Figure 3 shows that the electron temperature decreases with increasing discharge power for processes carried out in pure argon. This is in agreement with results from ${ }^{38}$ and attributed to an increased amount of sputtered species that are ionized upon electron impact resulting in decreased $\mathrm{T}_{\mathrm{e}} \mathrm{s}$. As the $\mathrm{N}_{2}$ content in the process gas is raised to 0.16 the $\mathrm{T}_{\mathrm{e}} \mathrm{s}$ show similar values of $1.8 \mathrm{eV} \pm 0.1 \mathrm{eV}$ for all applied average target powers, suggesting that the addition of low amounts of $\mathrm{N}_{2}$ to discharges conducted at average target powers up to $2400 \mathrm{~W}$ contributes to increased plasma densities. This may be due to the ionization according to (3) with an onset for appearance at $15.58 \mathrm{eV}$ as well as dissociative ionization according to (4) at $24.34 \mathrm{eV}^{39-42}$.

$$
\begin{aligned}
& \mathrm{N}_{2}+\mathrm{e}^{-} \rightarrow \mathrm{N}_{2}^{+}+2 \mathrm{e}^{-} \\
& \mathrm{N}_{2}+\mathrm{e}^{-} \rightarrow \mathrm{N}+\mathrm{N}^{+^{*}}+2 \mathrm{e}^{-}
\end{aligned}
$$

The mere dissociation (5) at $9.75 \mathrm{eV}$ or excitation (6) of the $\mathrm{N}_{2}$ molecule according to

$$
\begin{aligned}
& \mathrm{N}_{2}+\mathrm{e}^{-} \rightarrow \mathrm{N}+\mathrm{N}+\mathrm{e}^{-} \\
& \mathrm{N}_{2}+\mathrm{e}^{-} \rightarrow \mathrm{N}_{2}^{*}+\mathrm{e}^{-}
\end{aligned}
$$

do not contribute to an increased plasma density, since these reactions do not provide additional charge carriers. The results shown in figure 3 obtained at a $f_{N_{2} / A r}$ of 0.16 up to an average target power of $1200 \mathrm{~W}$ suggest that the ionization according to (3) may be most probable as it requires the least energy. As the target power is raised to $1800 \mathrm{~W}$ and $2400 \mathrm{~W}$ an additional excitation or dissociation of $\mathrm{N}_{2}$ is likely, since $\mathrm{T}_{\mathrm{e}}$ remains at $1.8 \mathrm{eV}$. As the discharge is carried out at a $f_{N_{2} / A r}$ of 0.28 the electron temperature is generally high and increases steadily as the average target power increase. The high electron temperatures agree with results from ion mass spectrometry showing reduced amounts of ionized species. The elevated electron temperatures indicate low plasma densities caused by the temporary change of the target surface chemistry, which in turn causes lowered sputter yields and secondary electron emission yields. As the target power increases the increasing $\mathrm{T}_{\mathrm{e}} \mathrm{s}$ suggest that the $\mathrm{N}_{2}$ molecule may also be activated according to (5) or (6), where dissociation or excitation (electron quenching) prevails ${ }^{15,39-41,43-44}$. Additionally, recombination reactions ${ }^{45}$ like

$\mathrm{N}_{2}^{+}+\mathrm{e}^{-} \rightarrow \mathrm{N}+\mathrm{N}^{*}$

may account for lowered plasma densities at $f_{N_{2} / A r}$ of 0.28 as the target power increases. An increasing electron temperature with increasing discharge power was also reported in references ${ }^{46-47}$. 


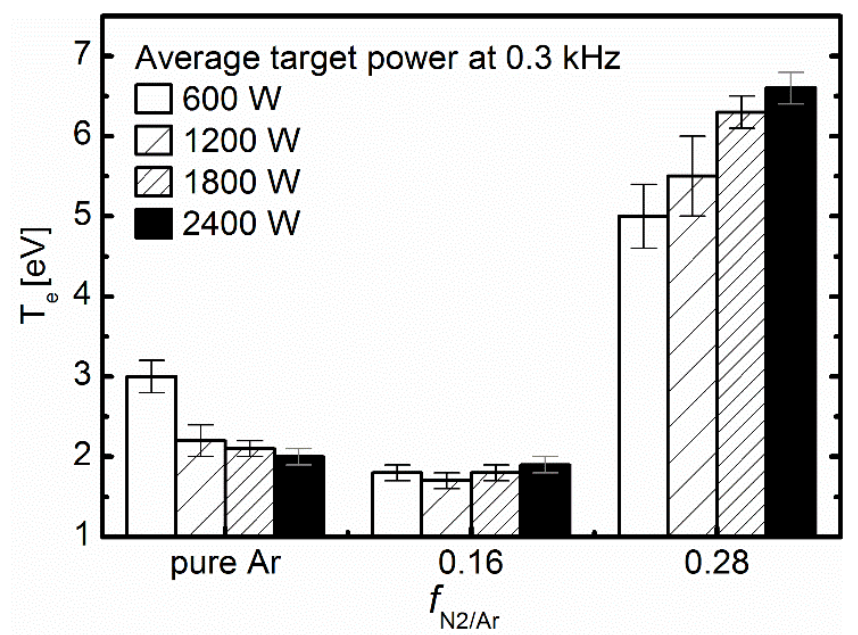

Figure 3: Electron temperature $\left(\mathrm{T}_{\mathrm{e}}\right)$ over the $\mathrm{N}_{2}$-to-Ar flow ratio $\left(f_{(\mathrm{N} 2 / \mathrm{Ar})}\right)$ for $\mathrm{Si} / \mathrm{Ar}$ and $\mathrm{Si} / \mathrm{Ar} / \mathrm{N}_{2}$ discharges conducted at $\mathrm{T}_{\mathrm{s}}=350{ }^{\circ} \mathrm{C}$, a process pressure of $400 \mathrm{mPa}$ and a pulse frequency of $0.3 \mathrm{kHz}$ with increasing average target powers.

Time-resolved plasma mass spectrometry was used to access the temporal evolution of the plasmas species in the $\mathrm{Si} / \mathrm{N}_{2} / \mathrm{Ar}$ plasma. Due to the similarity of the masses and the abundance of ions in the chosen experimental set-up, the IEDFs of isotopes ${ }^{15} \mathrm{~N},{ }^{29} \mathrm{Si}$, ${ }^{30} \mathrm{Si}$, and ${ }^{36} \mathrm{Ar}$ were recorded. Additionally, the IEDFs for mass 56 accounting for $\mathrm{SiN}_{2}{ }^{+}$or $\mathrm{Si}_{2}{ }^{+}$were measured. Time-resolved data are shown in figure 4 a) - c) as the discharges are operated at a process pressure of $400 \mathrm{mPa}$ for two different $\mathrm{N}_{2} / \mathrm{Ar}$ flow ratios and the case when $\mathrm{Si}$ is sputtered in pure Ar. Comparing the different discharges shown in figure 4 a) - c) it can be extracted that most prevalent precursor species in the plasma during the pulse on-time are $\mathrm{Si}^{+}, \mathrm{Si}^{2+}$ and/or $\mathrm{N}^{+}$. Larger ionized plasma species like ${ }^{36} \mathrm{Ar}$, the Ar cluster $2 \mathrm{Ar}$ and $\mathrm{SiN}$ or $\mathrm{Si}_{2}$ increase in intensity during the second part of the pulse on-time and reach their maximum intensity during pulse off times. This discrimination can mainly be attributed to the mass and dimension of these ionized species, their origin and the effect of gas rarefaction. The mass and dimension of the species determines its time of flight through the plasma as well as its probability for collision, which in turn will affect the corresponding delay time. The origin of the species affects the recorded delay time as ions originating from the target exhibit higher kinetic energies compared to species that are formed by recombination or fragmentation in the plasma ${ }^{37,48}$. Gas rarefaction affects the temporal evolution of intensities of the sputter gases, since the gas depletes temporally in front of the target when energetic, sputtered particles cause gas heating. The onset of gas depletion is usually observed as the target current peaks and many energetic species are sputtered. In this study, the effect is observed for discharges in pure $\mathrm{Ar}$ and for a low $\mathrm{N}_{2}$ /Ar flow ratio of 0.16 (cf. figure 1, and figure $4 \mathrm{a}$ ), b)). In the discharge containing an $f_{N_{2} / A r}$ of 0.30 , the signal of ${ }^{36} \mathrm{Ar}^{+}$is completely absent during pulse-on times. The absence of ${ }^{36} \mathrm{Ar}^{+}$is attributed to the fact that the overall amount of ionized $\mathrm{Ar}$ is lowered and further due to the limited natural abundance of $0.3336 \%$ of ${ }^{36} \mathrm{Ar}^{+}$, thus the effect of gas rarefaction may be concealed.

As indicated above, the temporal evolution of the ionized plasma species for the three different gas compositions (cf. figure 4 a) - c)) suggest a dependency on the $f_{N_{2} / A r}$. In figure 4 c) the plasma containing a $f_{\mathrm{N}_{2} / \mathrm{Ar}}$ of 0.30 shows a very distinct temporal discrimination of charged species with regards 
to their mass and dimension. This effect becomes less pronounced with decreasing $\mathrm{N}_{2}$ content in the plasma, which is ascribed to increasing particle energies as the $\mathrm{N}_{2}$ content in the plasma decreases (cf figure 2 a), b)). Furthermore, the time-resolved measurements show that, similarly to time averaged measurements, the overall ion intensity decreases as more $\mathrm{N}$ is added to the plasma and is also confirmed by Langmuir probe measurements (cf. figure 3).

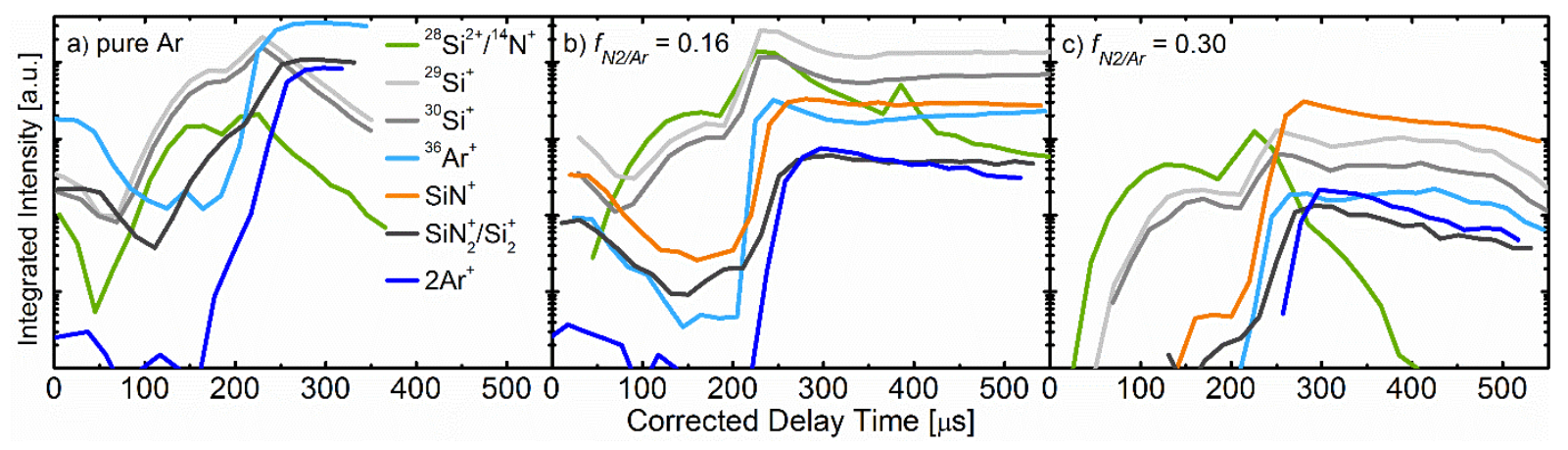

Figure 4 a) - c): Time-resolved positive ion mass spectrometry measurements integrated over the ion energy and corrected by the time-of-flight within the mass spectrometer of $\mathrm{Si} / \mathrm{Ar} / \mathrm{N}_{2}$ discharges using a pulse frequency of 0.3 $\mathrm{kHz}$, an average target power of $1000 \mathrm{~W}$ and a deposition pressure of $400 \mathrm{mPa}$; a) pure Ar, b) $f_{\mathrm{N} 2 / \mathrm{Ar}}=0.16$ and c) $f_{N 2 / A r}=0.30$. 


\subsection{Deposition parameters influencing the $\mathbf{N}$ content of $\operatorname{SiN}_{x}$ coatings and impact of the film $\mathbf{N}$ contents on $\mathrm{SiN}_{x}$ properties}

\subsection{1 $\mathrm{N}_{2}$-to-Ar flow ratio}

As discussed above, the $\mathrm{SiN}_{\mathrm{x}}$ deposition process characteristics and stability are controlled to a high extent by the $f_{N_{2} / A r}$ and this is also reflected in the properties of $\operatorname{SiN}_{\mathrm{x}}$. In figure 5 , the growth rate $\left(\mathrm{R}_{\mathrm{G}}\right)$ and the $\mathrm{N}$ content of $\mathrm{SiN}_{\mathrm{x}}$ films deposited at a pulse energy of $6 \mathrm{Ws}$ using different $f_{\mathrm{N}_{2} / \mathrm{Ar}}$ between 0 and 0.30 are shown. As expected, increasing $f_{N_{2} / A r}$ lead to increasing $\mathrm{N}$ contents in the $\mathrm{SiN}_{\mathrm{x}}$ films and to decreasing deposition rates. This is in agreement with conclusions drawn from the current waveforms (cf. figure 1a)), the lowered negative cathode potential as $f_{N_{2} / A r}$ increases (cf. figure $1 \mathrm{~b}$ )), and the results from plasma mass spectrometry (cf. figure 2 and 4). The latter shows decreased abundance of all cations in the plasma as $f_{N_{2} / A r}$ increases, leading - in a first approximation - to the conclusion that the sputter yield and hence, the growth rate $\left(\mathrm{R}_{\mathrm{G}}\right)$ decreases as the target is operated in transition or poisoned mode. This is commonly observed for reactive magnetron sputtering discharges ${ }^{15,49}$.

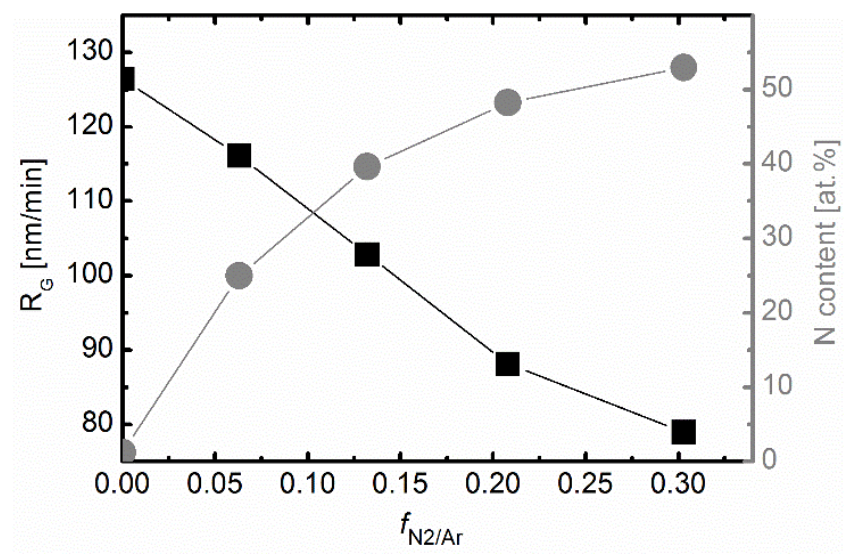

Figure 5: Growth rate $\left(\mathrm{R}_{\mathrm{G}}\right.$, black squares) and $\mathrm{N}$ contents (grey circles) in $\mathrm{SiN}_{\mathrm{x}}$ films as a function of the $\mathrm{N}_{2}$-toAr flow ratio $\left(f_{\mathrm{N} 2 / \mathrm{Ar}}\right)$ obtained from films deposited at a substrate temperature of $350{ }^{\circ} \mathrm{C}$ using a pulse energy of 6 Ws, and a process pressure of $400 \mathrm{mPa}$.

Figure 6 a) - d) presents the influence of increasing $\mathrm{N}$ contents on the Si bond structure. As the $\mathrm{N}$ content in the Si-matrix increases, the signals of $\mathrm{Si} 2 \mathrm{p}_{3 / 2}$ and $\mathrm{Si} 2 \mathrm{p}_{1 / 2}$ at binding energies of $99.0 \mathrm{eV}$ and $99.7 \mathrm{eV}$, respectively, decrease, while different $\mathrm{Si}-\mathrm{N}$ bond types at $100.3 \mathrm{eV}, 101.4 \mathrm{eV}$, and $102 \mathrm{eV}$ increase ${ }^{50}$. The different binding energies of the Si-N bonds indicated in figure 6 originate due to the different tetrahedral bond regimes of $\mathrm{SiN}_{\mathrm{x}}$, i.e. Si-Si-N, Si-N-N, and to a smaller extent the presence of nearestneighbor effects (secondary chemical shifts). Here, the Si2p binding energy is affected by the bond type of the neighboring Si atoms. Moreover, the spectra components are broadened as more $\mathrm{N}$ is incorporated in the Si matrix. The FWHM of the Si2 $\mathrm{p}_{3 / 2}$ component in the spectrum obtained from pure $\mathrm{Si}$ is $0.7 \mathrm{eV}$ (cf. figure 6 a)), while the FWHM of the contribution assigned to Si-N-(-N) bonds of the sample containing 49 at.\% N (cf. figure $6 \mathrm{~d}$ )) amounts to $1.7 \mathrm{eV}$. Since $\Theta-2 \Theta$ XRD scans showed that the here investigated $\mathrm{SiN}_{\mathrm{x}}$ coatings are X-ray amorphous (cf. supporting information), the broadening of the XPS core level components is mainly attributed to the stochastic nature of the bond formation process, where 
repeating unit cells, and thus well-defined binding energies associated with a given bond type are lacking ${ }^{50}$. $\mathrm{Ar}^{+}$sputter cleaning increased the FWHM of the components by a maximum of $0.2 \mathrm{eV}$.

At a N content of 49 at.\%, the Si2p core level comprises merely one component arising from Si-N bonds and Si-Si bonds are absent (cf. figure $6 \mathrm{~d}$ )). Moreover, as the $\mathrm{N}$ content in the coatings increases and approaches 49 at.\%, the Ar content decreases from 2 at.\% to 0 at.\%, while a slight increase of oxygen from $\sim 2$ at. $\%$ to $\sim 4$ at.\% was recorded. The incorporation of carbon was $<1$ at. $\%$ and appeared unaffected by the $\mathrm{N}$ content of the coatings.

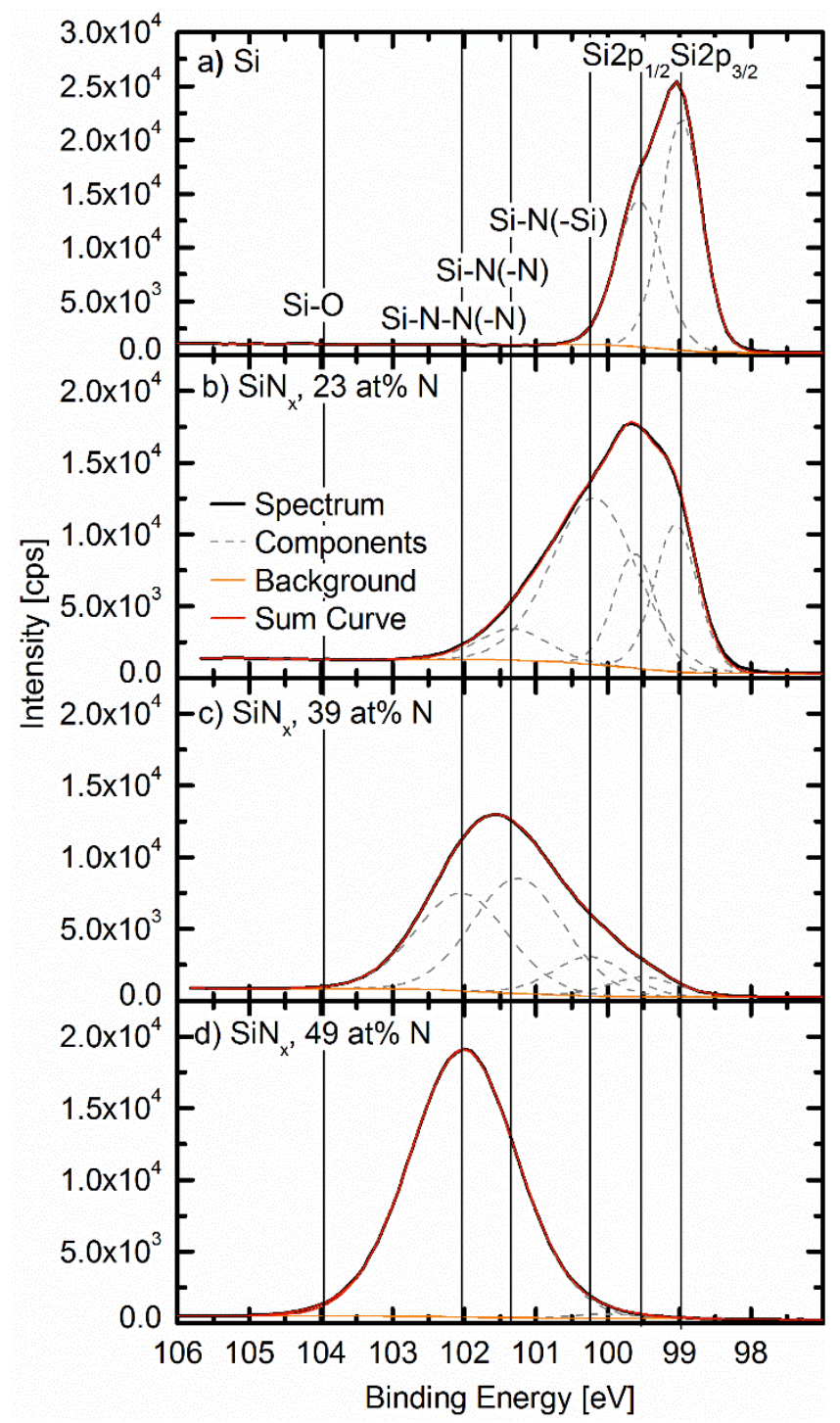

Figure 6 a) - d): XPS core level spectra of the Si2p region for a) pure Si, b) $\operatorname{SiN}_{x}$ containing 23 at.\% N, c) $\operatorname{SiN}_{x}$ containing 39 at.\% N, and d) $\mathrm{SiN}_{\mathrm{x}}$ containing 49 at.\% N. The spectra were acquired after $\mathrm{Ar}^{+}$sputter cleaning.

Figure $7 \mathrm{a}$ ) and b) present the impact of an increased $\mathrm{N}$ content in the coatings on the compressive residual stress and the density as well as the hardness $(\mathrm{H})$ and the Young's modulus, respectively. As demonstrated in figure 7 a), increasing $\mathrm{N}$ contents in the $\mathrm{SiN}_{\mathrm{x}}$ matrix result in increasing film densities 
up to $2.98 \mathrm{~g} / \mathrm{cm}^{3}$, approaching the density of $\mathrm{Si}_{3} \mathrm{~N}_{4}$ of $3.2 \mathrm{~g} / \mathrm{cm}^{3}$. The evolution of the coating density agrees well with the tabulated bond length of Si-N of $\sim 170 \mathrm{pm}$ compared to the bond length of Si-Si of $233 \mathrm{pm}$. At the same time the residual compressive stresses increase up to -1.5 GPa. High compressive stresses in the GPa range were also observed by Burkhardt and Marvel ${ }^{51}$, where the coefficient of thermal expansion of sputtered $\mathrm{SiN}_{\mathrm{x}}\left(\mathrm{CTE}_{\mathrm{SiN}}\right)$ at $350^{\circ} \mathrm{C}$ was estimated to $3.3 \times 10^{-6}{ }^{\circ} \mathrm{C}^{-1}$ and that of $\mathrm{Si}\left(\mathrm{CTE}_{\mathrm{Si}}\right)$ to $3.7 \times 10^{-6}{ }^{\circ} \mathrm{C}^{-1}$. The observed increase of the residual compressive stress with increasing $\mathrm{N}$ content of the $\mathrm{SiN}_{\mathrm{x}}$ films may result from a combination of the differences in CTE of the film and substrate material, the reduced bond $\mathrm{Si}-\mathrm{N}$ bond lengths and the related increased $\mathrm{SiN}_{\mathrm{x}}$ densities as well as an increasing number of polyatomic film forming species in the plasma as the $f_{N_{2} / A r}$ is raised up to $\sim 0.30$. An elevated amount of complex molecules in the sputter plasma was proposed by Nir et al. ${ }^{52}$ to contribute to higher film stresses, due to their constrained mobility at the growing film surface. In this study the relative amount of ionized molecules increased as the $f_{N_{2} / A r}$ increases up to 0.30 (cf. figure 4 c)).

The hardness and elastic modulus extracted for the $\mathrm{SiN}_{\mathrm{x}}$ coatings with increasing $\mathrm{N}$ contents show a similar trend as the coating density. The linear dependence of the hardness on the $\mathrm{SiN}_{\mathrm{x}}$ coating density is shown in the inset in figure $7 \mathrm{~b}$ ). Hence, the increase of the hardness can be attributed to an increased $\mathrm{SiN}_{\mathrm{x}}$ density as the $\mathrm{N}$ content of the material increases. Similar observations are also reported in references ${ }^{17,53-54}$.

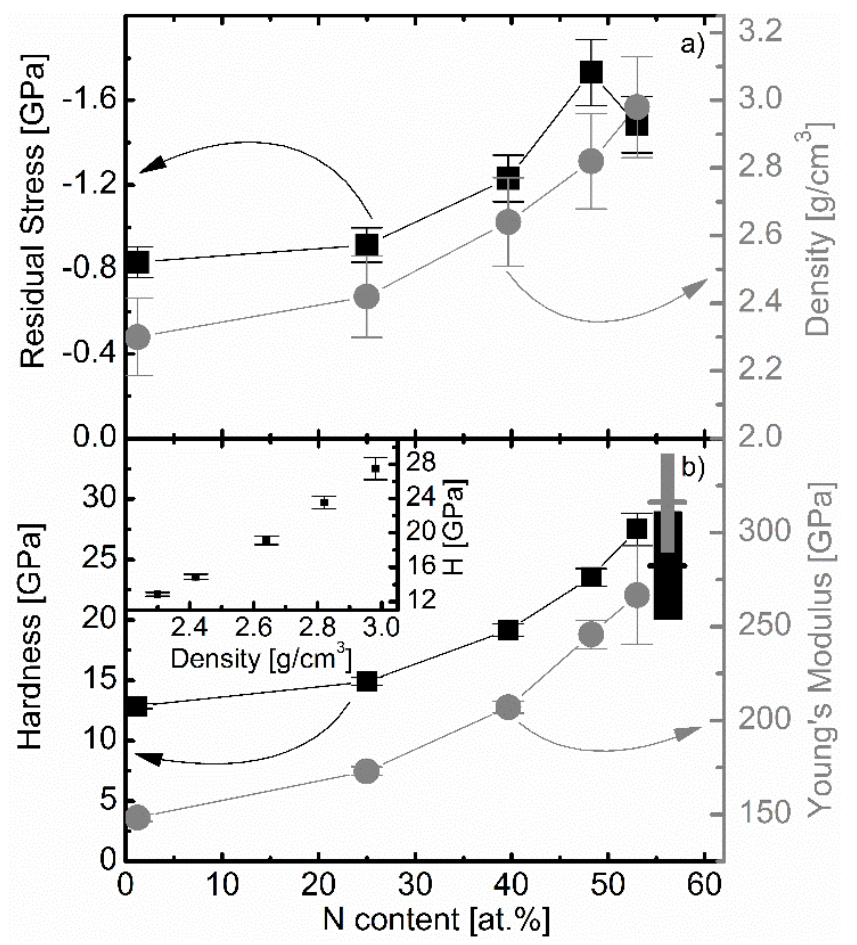

Figure 7 a) and b): a) Residual stress (black squares) and density (grey circles) as well as b) Hardness (black squares) and Young's modulus (grey circles) for films with increasing $\mathrm{N}$ contents deposited at a substrate temperature of $350{ }^{\circ} \mathrm{C}$ using a pulse energy of $6 \mathrm{Ws}$, and a process pressure of $400 \mathrm{mPa}$. In b) the hardness (black rectangle) and Young's modulus (grey rectangle) from a $\mathrm{Si}_{3} \mathrm{~N}_{4}$ reference ${ }^{3}$ are shown. 


\subsubsection{HiPIMS power settings}

The $\mathrm{N}$ content in the $\mathrm{SiN}_{\mathrm{x}}$ coatings is also influenced by the applied energy per pulse $\left(\mathrm{E}_{\mathrm{p}} \mathrm{P}\right)$ as $\mathrm{SiN}_{\mathrm{x}}$ coatings are deposited at $\mathrm{N}_{2}$ deficiency, accounting for $f_{N_{2} / A r}<0.28$ (at a deposition pressure of 400 $\mathrm{mPa}$ and $\mathrm{T}_{\mathrm{s}}=350{ }^{\circ} \mathrm{C}$ ) in the plasma. In such $\mathrm{N}$-depleted $\mathrm{Si} / \mathrm{N}_{2} / \mathrm{Ar}$ discharges, the ratio of sputtered $\mathrm{Si}$ to the availability of dissociated or ionized $\mathrm{N}_{2}$ is inversely proportional to the $\mathrm{N}$ content in the $\operatorname{SiN}_{\mathrm{x}}$ coating. This is exemplified in figure 8 a), where the Si/N ratios of $\operatorname{SiN}_{\mathrm{x}}$ coatings deposited at $f_{\mathrm{N}_{2} / \mathrm{Ar}}$ of 0.16 and 0.28 are shown over the applied average target power. Additionally, the growth rates of the corresponding coatings are shown in figure $8 \mathrm{~b}$ ). The coatings were deposited using either a constant $\mathrm{E}_{\mathrm{pP}}$ (implying proportionally increasing pulse frequencies as the average target power increases) or a constant pulse frequency (implying that the $\mathrm{E}_{\mathrm{pP}}$ increases as the average target power is increased). Obvious are increasing $\mathrm{Si} / \mathrm{N}$ ratios with increasing average target power of films deposited at $f_{N_{2} / A r}=0.16$ with a pulse frequency of $0.3 \mathrm{kHz}$ and increasing $\mathrm{E}_{\mathrm{pP}}$ (cf. figure $8 \mathrm{a}$ ) grey circles). Hence, the $\mathrm{N}$ content in the coating decreases as the $\mathrm{E}_{\mathrm{pP}}$ is raised. For $\mathrm{SiN}_{\mathrm{x}}$ coatings deposited at an $\mathrm{E}_{\mathrm{pP}}$ of $3 \mathrm{Ws}$ (corresponding to increasing pulse frequencies as the average target power is raised), the obtained $\mathrm{Si} / \mathrm{N}$ ratios are comparable over the range of applied average target powers (cf. figure 8 a) black squares). This can be explained on the basis of the Si-sputter yield and growth rates (cf. figure $8 \mathrm{~b}$ )); increasing pulse frequencies influence the sputter yield to a lower extent, while increasing average target powers have the strongest effect, since the sputter yield increases with the average target voltage (cf. figure 3). The average target voltage varied between $500 \mathrm{~V}$ and $600 \mathrm{~V}$ for the investigated processes, applying the lowest $\mathrm{E}_{\mathrm{pP}}$ of $1.5 \mathrm{Ws}$ and the highest $\mathrm{E}_{\mathrm{pP}}$ of $7.5 \mathrm{Ws}$, respectively. According to TRIM simulations ${ }^{55}$ the Si sputter yield in $\mathrm{Ar}$ is $0.38 \mathrm{at} / \mathrm{ion}$ at an average target voltage of $500 \mathrm{~V}$ and $0.46 \mathrm{at} / \mathrm{ion}$ at $600 \mathrm{~V}$.

As the $\mathrm{SiN}_{\mathrm{x}}$ coatings are deposited in transition mode, accounting for $f_{\mathrm{N}_{2} / \mathrm{Ar}}$ ranging between 0.28 and 0.31 (at a deposition pressure of $400 \mathrm{mPa}$ and $\mathrm{T}_{\mathrm{s}}=350{ }^{\circ} \mathrm{C}$ ), the $\mathrm{Si} / \mathrm{N}$ ratios decrease and are only slightly influenced by the HiPIMS power settings, since an adequate amount of activated $\mathrm{N}$ species is existent. These $\mathrm{N}$ species contribute to the formation of a N-rich compound layer at the target surface during pulse-off times. As can be drawn from figure 8, a slight trend towards higher $\mathrm{Si} / \mathrm{N}$ ratios is also observed as $\mathrm{SiN}_{\mathrm{x}}$ coatings are deposited with increasing $\mathrm{E}_{\mathrm{pP}}$ in transition mode. This is again attributed to increasing Si-sputter yields and the fact that operating at an $f_{N_{2} / A r}$ of 0.28 renders the lower region of the transition mode. From figure 8 as well as figures 1 and 2, it is evident that the extent of compound layer formation increases not only with the $f_{N_{2} / A r}$, but also with decreasing average target power, while the sputter rate of metallic particles is inversely proportional to both. 


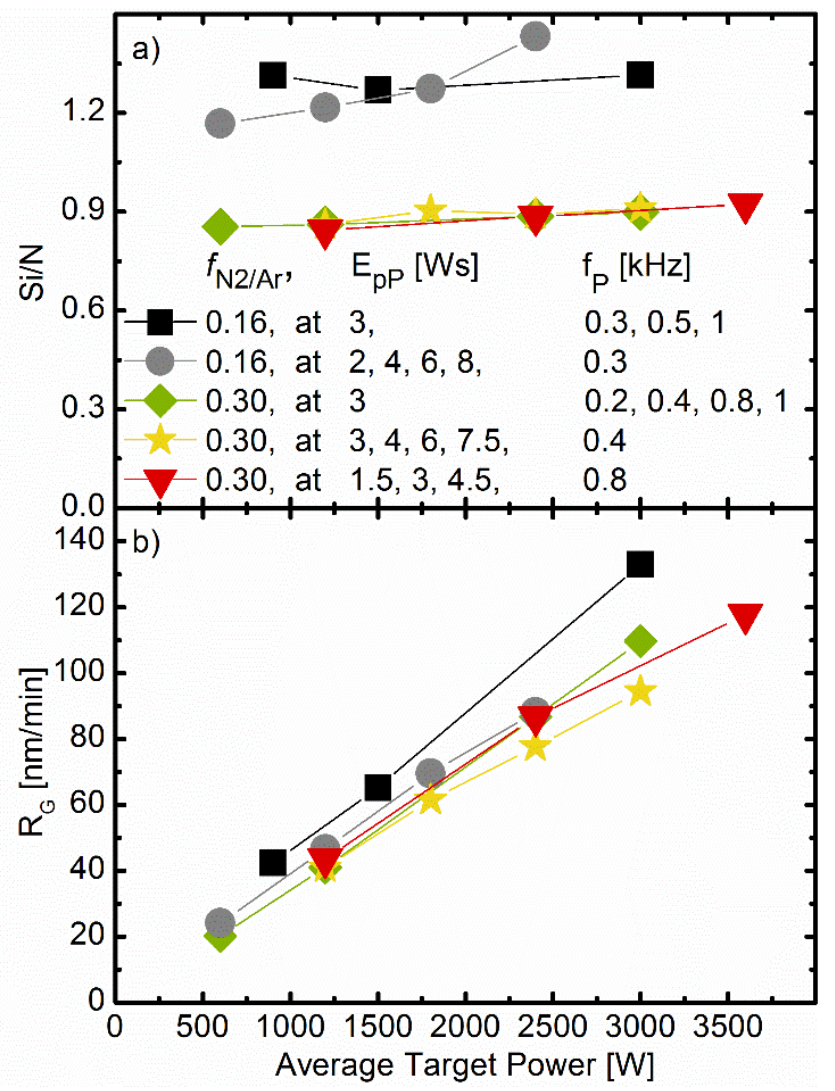

Figure 8 a) and b): a) Si/N ratios as obtained by XPS measurements and b) the corresponding growth rates $\left(\mathrm{R}_{\mathrm{G}}\right)$ over the applied average target power. $\mathrm{SiN}_{\mathrm{x}}$ coatings were deposited using a total process pressure of $400 \mathrm{mPa}$ and a substrate temperature of $350^{\circ} \mathrm{C}$. Applied process settings such as the $\mathrm{N}_{2} / \mathrm{Ar}$ flow ratio $\left(f_{\mathrm{N} 2 / \mathrm{Ar}}\right)$, the energy per pulse $\left(\mathrm{E}_{\mathrm{pP}}\right)$ and the pulse frequency $\left(\mathrm{f}_{\mathrm{p}}\right)$ are indicated. Errors as for the $\mathrm{Si} / \mathrm{N}$ ratio are estimated to be \pm 0.03 and for $\mathrm{R}_{\mathrm{G}} \pm 3 \mathrm{~nm} / \mathrm{min}$.

\subsubsection{Substrate temperature}

Figure 9 presents cross-sectional SEM images of $\mathrm{SiN}_{\mathrm{x}}$ coatings deposited at a substrate temperature of a) $190{ }^{\circ} \mathrm{C}$, b) $350{ }^{\circ} \mathrm{C}$, c) $420^{\circ} \mathrm{C}$, and d) $510{ }^{\circ} \mathrm{C}$. As can be seen in figure 9 , the dense, featureless morphology of the $\mathrm{SiN}_{\mathrm{x}}$ coatings does not change significantly as the substrate temperature is increased. Facets in figure $9 \mathrm{c}$ ) and d) are mainly attributed to the sample preparation by wafer cleavage. Owing to the insulating nature of the presented coatings, the microscope brightness and contrast settings were chosen as to emphasize the coating morphology rather than the $\mathrm{SiN}_{\mathrm{x}} / \mathrm{Si}(001)$ interface. However, the $\mathrm{SiN}_{\mathrm{x}} / \mathrm{Si}(001)$ interfaces were identified during imaging at intensified contrast and brightness settings and are indicated in figure 9.

The $\mathrm{N}$ content in the $\mathrm{SiN}_{\mathrm{x}}$ coatings decreases slightly with increasing substrate temperatures. From figure 10 it is evident that the $\mathrm{N}$ contents decrease from 53.7 at.\% to 50.5 at.\% as the substrate temperature increases from $190{ }^{\circ} \mathrm{C}$ to $510{ }^{\circ} \mathrm{C}$. A similar observation was reported in reference ${ }^{17}$. The 
growth rate appears not significantly influenced by the substrate temperature. These observations are attributed to an increased ad-atom mobility, which leads to

i) an increased probability of $\mathrm{N}-\mathrm{N}$ recombination (based on our theoretical results)

ii) an increased probability of chemical sputtering (desorption) of N-containing film forming species ${ }^{56-57}$ at the substrate surface especially with the presence of background gas

iii) the effect that film forming species can select more energetically favorable bonding sites.

As the substrate temperature increases, amounts of $\mathrm{O}, \mathrm{C}$, and $\mathrm{Ar}$ in the coatings increase from 0.9 at.\% to 4.2 at.\%, 0.2 at.\% to 1.3 at.\% and 0 at.\% to 0.2 at.\%, respectively. At the same time a trend towards lower densities is recorded, which decrease from $2.9 \mathrm{~g} / \mathrm{cm}^{3}$ at $190{ }^{\circ} \mathrm{C}$ to $2.6 \mathrm{~g} / \mathrm{cm}^{3}$ at $520{ }^{\circ} \mathrm{C}$. Both, the increased amount of contaminates and lowered coating densities at $520^{\circ} \mathrm{C}$ may result due to elevated desorption of contaminants from the chamber walls. Although cross-sectional SEM micrographs do not show significant changes of the coating morphology as the substrate temperature increases (cf. figure 9) the reduced film density at elevated substrate temperatures indicates that the $\mathrm{SiN}_{\mathrm{x}}$ coatings become increasingly porous. This, in turn, leads to an amplified $\mathrm{O}$ and $\mathrm{C}$ uptake of the films upon exposure to air. Consequently, optimal substrate temperatures for the deposition of $\mathrm{SiN}_{\mathrm{x}}$ using rHiPIMS are above $150^{\circ} \mathrm{C}$ and below $400^{\circ} \mathrm{C}$. 


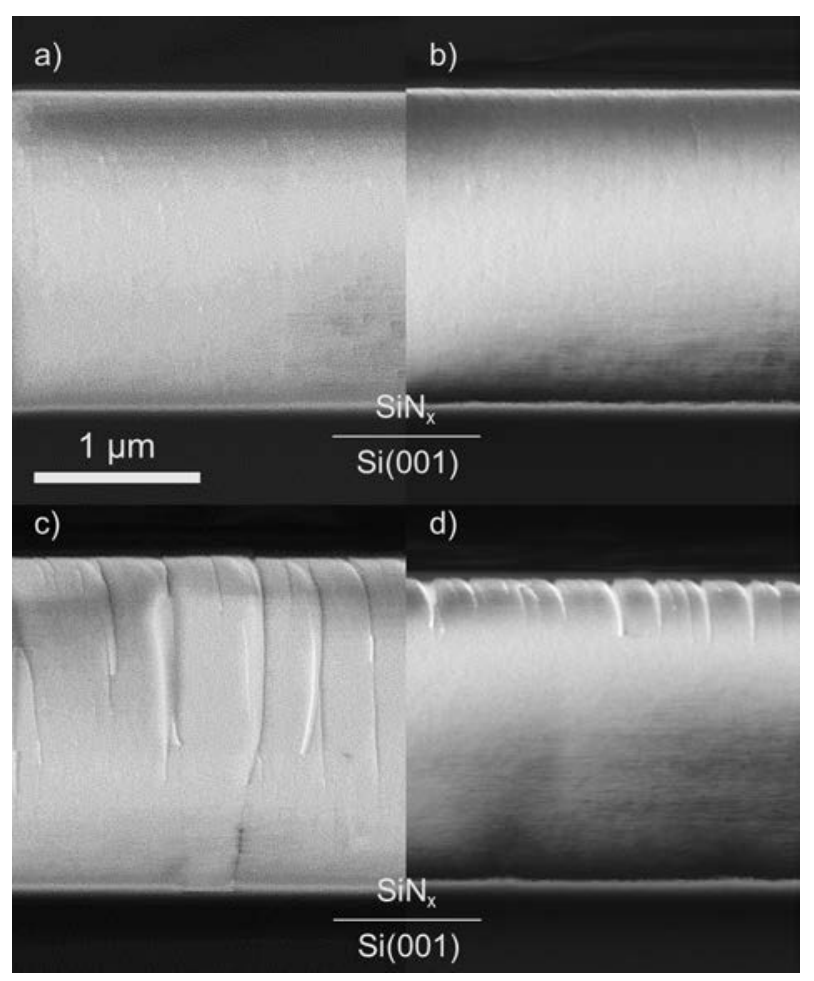

Figure 9: Cross-sectional SEM images of $\mathrm{SiN}_{\mathrm{x}}$ coatings deposited at a substrate temperature of a) $190{ }^{\circ} \mathrm{C}$, b) 350 ${ }^{\circ} \mathrm{C}$, c) $420{ }^{\circ} \mathrm{C}$, and d) $510{ }^{\circ} \mathrm{C}$. The magnification was set to the same value during acquisition. $\mathrm{The}_{\mathrm{SiN}} / \mathrm{Si}(001)$ interface was observed during acquisition at intensified contrast and brightness settings.

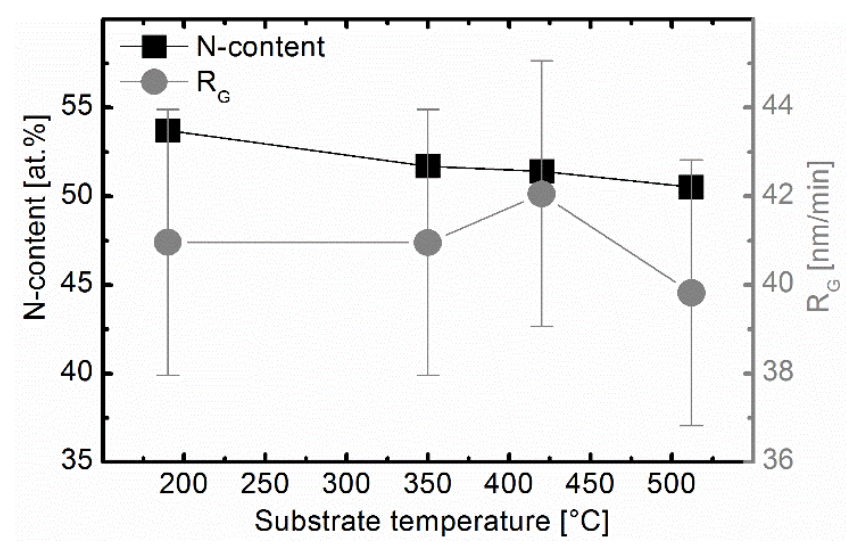

Figure 10: $\mathrm{N}$ content as obtained by XPS and growth rate of $\mathrm{SiN}_{\mathrm{x}}$ coatings deposited at $190{ }^{\circ} \mathrm{C}, 350{ }^{\circ} \mathrm{C}, 420{ }^{\circ} \mathrm{C}$, and $510{ }^{\circ} \mathrm{C}$. The standard deviation for the presented $\mathrm{N}$ contents is $<0.3$ at.\%.

\section{Summary and Conclusions}

Growth conditions for rHiPIMS processes, influencing the $\mathrm{N}$ content of $\mathrm{SiN}_{\mathrm{x}}$ coatings were investigated. The Si magnetron sputter discharge and the $\mathrm{SiN}_{\mathrm{x}}$ coating properties are heavily influenced by the amount of $\mathrm{N}_{2}$ in the plasma. Moreover, the applied target power as well as the substrate temperature were found to influence the $\mathrm{N}$ contents in $\mathrm{SiN}_{\mathrm{x}}$ coatings and thus the coating properties - although to a much lower extent. While increasing $\mathrm{N}_{2}$-to-Ar ratios in the sputter plasma yield rapidly increasing $\mathrm{N}$ contents up to 
$\sim 50$ at.\%, an increasing target power and substrate temperatures above $350{ }^{\circ} \mathrm{C}$ result in up to 6 at. $\%$ and 4 at.\% lower $\mathrm{N}$ contents in the coatings, respectively. The target surface condition determines to which extent the applied average target power influence the $\mathrm{N}$ contents in $\mathrm{SiN}_{\mathrm{x}}$ coatings. Under metallic target surface conditions, accounting for $\mathrm{N}_{2}$-to-Ar flow ratios below $28 \%$, increasing target powers, yield significantly higher $\mathrm{Si} / \mathrm{N}$ ratios. The $\mathrm{Si} / \mathrm{N}$ ratios are hardly affected by an increase of the average target power as the target is operated in transition mode corresponding to $\mathrm{N}_{2}$-to-Ar flow ratio between 0.28 and 0.31 .

Langmuir probe and ion mass spectrometry measurements in $\mathrm{Si} / \mathrm{Ar} / \mathrm{N}_{2}$ discharges showed that low $\mathrm{N}_{2}$ to-Ar flow ratios of $~ 0.16$ induce an increased plasma density due to the dissociation and ionization of $\mathrm{N}_{2}$. As the $\mathrm{N}_{2}$-to-Ar flow ratio increases to 0.28 reduced plasma densities and ion count rates were observed and ascribed to a temporally poisoned target surface and an altered activation path of $\mathrm{N}_{2}$. At the same time the $\mathrm{SiN}_{\mathrm{x}}$ growth rates decrease and the coating density, residual compressive stress, hardness as well as the Young's modulus increase. SiN $_{\mathrm{x}}$ coatings containing $~ 50$ at.\% $\mathrm{N}$ show a bond configuration where Si-N bonds prevail and $\mathrm{Si}-\mathrm{Si}$ bonds are absent. Such coatings were grown in discharges using $\mathrm{N}_{2}$-to-Ar flow ratios between 0.28 and 0.31 . These coatings show a comparatively high density of $2.98 \mathrm{~g} / \mathrm{cm}^{3}$ and hardness and of up to $27.5 \mathrm{GPa}$ and are suited for the further evaluation for bio-medical applications. 


\section{Supporting Information}

XRD $\Theta-2 \Theta$ scans of a sputter deposited Si coating and representative $\operatorname{SiN}_{x}$ coatings

\section{Acknowledgments}

The research leading to these results has received funding from the European Union's Seventh Framework Program (FP7/2007-2013) under the LifeLongJoints Project, Grant Agreement no. GA310477. S.Sc. acknowledges the support by the Carl Trygger Foundation for Scientific Research (grant number CTS 14:431). L.H. and H.H. acknowledges the Swedish Government Strategic Research Area in Materials Science on Functional Materials at Linköping University (Faculty Grant SFO-Mat-LiU No. 2009-00971) for financial support. 


\section{References}

1. Maloney, J. M.; Lipka, S. A.; Baldwin, S. P., In vivo Biostability of CVD Silicon Oxide and Silicon Nitride Films. Mater. Res. Soc. Symp. Proc. 2005, 872, 279-284.

2. Shi, Z.; Wang, Y.; Du, C.; Huang, N.; Wang, L.; Ning, C., Silicon Nitride Films for the Protective Functional Coating: Blood Compatibility and Biomechanical Property Study. J. Mech. Behav. Biomed. Mater. 2012, 16 (1), 9-20.

3. Pettersson, M.; Tkachenko, S.; Schmidt, S.; Berlind, T.; Jacobson, S.; Hultman, L.; Engqvist, H.; Persson, C., Mechanical and Tribological Behavior of Silicon Nitride and Silicon Carbon Nitride Coatings for Total Joint Replacements. J. Mech. Behav. Biomed. Mater. 2013, 25, 41-47.

4. Pettersson, M.; Berlind, T.; Schmidt, S.; Jacobson, S.; Hultman, L.; Persson, C.; Engqvist, H., Structure and Composition of Silicon Nitride and Silicon Carbon Nitride Coatings for Joint Replacements. Surf. Coat. Technol. 2013, 235, 827-834.

5. McEntire, B. J.; Bal, B. S.; Rahaman, M. N.; Chevalier, J.; Pezzotti, G., Ceramics and Ceramic Coatings in Orthopaedics. J. Eur. Ceram. Soc. 2015, 35 (16), 4327-4369.

6. Neumann, A.; Reske, T.; Held, M.; Jahnke, K.; Ragoß, C.; Maier, H. R., Comparative Investigation of the Biocompatibility of Various Silicon Nitride Ceramic Qualities In vitro. J. Mater. Sci.: Mater. Med. 2004, 15 (10), 1135-1140.

7. Herrmann, M.; Schilm, J.; Michael, G.; Meinhardt, J.; Flegler, R., Corrosion of Silicon Nitride Materials in Acidic and Basic Solutions and under Hydrothermal Conditions. J. Eur. Ceram. Soc. 2003, 23 (4), 585-594. 
8. Laarz, E.; Zhmud, B. V.; Bergström, L., Dissolution and Deagglomeration of Silicon Nitride in Aqueous Medium. J. Am. Ceram. Soc. 2000, 83 (10), 2394-2400.

9. Pettersson, M.; Bryant, M.; Schmidt, S.; Engqvist, H.; Hall, R. M.; Neville, A.; Persson, C., Dissolution Behaviour of Silicon Nitride Coatings for Joint Replacements. Mater. Sci. Eng., C 2016, 62, 497-505.

10. Gupta, M.; Rathi, V. K.; Thangaraj, R.; Agnihotri, O. P.; Chari, K. S., The Preparation, Properties and Applications of Silicon Nitride Thin Films Deposited by Plasma-Enhanced Chemical Vapor Deposition. Thin Solid Films 1991, 204 (1), 77-106.

11. Morin, P.; Raymond, G.; Benoit, D.; Maury, P.; Beneyton, R., A Comparison of the Mechanical Stability of Silicon Nitride Films Deposited with Various Techniques. Appl. Surf. Sci. 2012, 260 (0), 69-72.

12. Ohring, M., Chapter 6 - Chemical Vapor Deposition. In Materials Science of Thin Films (Second Edition), Academic Press: San Diego, CA, USA, 2002, pp 277-355.

13. Jansen, F.; Machonkin, M. A., Wear Properties of Tetrahedrally Bonded Amorphous Thin Films. Thin Solid Films 1986, 140 (2), 227-235.

14. Oliveira, A.; Cavaleiro, A.; Vieira, M. T., Production and Characterization of Si-N Films Obtained by r.f. Magnetron Sputtering. Surf. Coat. Technol. 1993, 60 (1-3), 463-467.

15. Signore, M. A.; Sytchkova, A.; Dimaio, D.; Cappello, A.; Rizzo, A., Deposition of Silicon Nitride Thin Films by RF Magnetron Sputtering: A Material and Growth Process Study. Opt. Mater. 2012, 34 (4), 632-638. 
16. Yau, B.-S.; Huang, J.-L., Effects of Nitrogen Flow on R.F. Reactive Magnetron Sputtered Silicon Nitride Films on High Speed Steel. Surf. Coat. Technol. 2004, 176 (3), 290-295.

17. Vila, M.; Cáceres, D.; Prieto, C., Mechanical Properties of Sputtered Silicon Nitride Thin Films. J. Appl. Phys. 2003, 94 (12), 7868-7873.

18. Depla, D.; Mahieu, S.; Greene, J. E., Chapter 5 - Sputter Deposition Processes. In Handbook of Deposition Technologies for Films and Coatings, 3rd ed.; Martin, P. M., Ed. William Andrew Publishing: Boston, 2010, pp 253-296.

19. Lattemann, M.; Ulrich, S.; Holleck, H.; Stüber, M.; Leiste, H., Characterisation of Silicon Carbide and Silicon Nitride Thin Films and $\mathrm{Si}_{3} \mathrm{~N}_{4} /$ SiC Multilayers. Diamond Relat. Mater. 2002, 11 (3-6), 1248-1253.

20. Pusch, C.; Hoche, H.; Berger, C.; Riedel, R.; Ionescu, E.; Klein, A., Influence of the PVD Sputtering Method on Structural Characteristics of SiCN-Coatings - Comparison of RF, DC and HiPIMS Sputtering and Target Configurations. Surf. Coat. Technol. 2011, 205, Supplement 2 (0), S119-S123.

21. Dickson, M.; Qian, F.; Hopwood, J., Quenching of Electron Temperature and Electron Density in Ionized Physical Vapor Deposition. J. Vac. Sci. Technol., A 1997, 15 (2), 340-344.

22. Macak, K.; Kouznetsov, V.; Schneider, J.; Helmersson, U.; Petrov, I., Ionized Sputter Deposition using an Extremely High Plasma Density Pulsed Magnetron Discharge. J. Vac. Sci. Technol., A 2000, 18 (4), 1533-1537. 
23. Kouznetsov, V.; Macak, K.; Schneider, J. M.; Helmersson, U.; Petrov, I., A Novel Pulsed Magnetron Sputter Technique utilizing Very High Target Power Densities. Surf. Coat. Technol. 1999, 122 (2-3), 290-293.

24. Goyenola, C., Nanostructured Carbon-based Thin Films: Prediction and Design. Ph.D. Thesis, Linköping Universiy, Linköping, Sweden: 2015; p 1-153.

25. Frisch, M. J.; Trucks, G. W.; Schlegel, H. B.; Scuseria, G. E.; Robb, M. A.; Cheeseman, J. R.; Scalmani, G.; Barone, V.; Mennucci, B.; Petersson, G. A.; Nakatsuji, H.; Caricato, M.; Li, X.; Hratchian, H. P.; Izmaylov, A. F.; Bloino, J.; Zheng, G.; Sonnenberg, J. L.; Hada, M.; Ehara, M.; Toyota, K.; Fukuda, R.; Hasegawa, J.; Ishida, M.; Nakajima, T.; Honda, Y.; Kitao, O.; Nakai, H.; Vreven, T.; Montgomery, J. A. J.; E., P. J.; Ogliaro, F.; Bearpark, M.; Heyd, J. J.; Brothers, E.; Kudin, K. N.; Staroverov, V. N.; Kobayashi, R.; Normand, J.; Raghavachari, K.; Rendell, A.; Burant, J. C.; Iyengar, S. S.; Tomasi, J.; Cossi, M.; Rega, N.; Millam, J. M.; Klene, M.; Knox, J. E.; Cross, J. B.; Bakken, V.; Adamo, C.; Jaramillo, J.; Gomperts, R.; Stratmann, R. E.; Yazyev, O.; Austin, R.; Cammi, A. J.; Pomelli, C.; Ochterski, J. W.; Martin, R. L.; Morokuma, K.; Zakrzewski, V. G.; Voth, G. A.; Salvador, P.; Dannenberg, J. J.; Dapprich, S.; D., D. A.; Farkas, Ö.; Foresman, J. B.; Ortiz, J. V.; Cioslowski, J.; Fox, D. J., Gaussian09. Gaussian, Inc., Wallingford CT: 2009.

26. Perdew, J. P.; Chevary, J. A.; Vosko, S. H.; Jackson, K. A.; Pederson, M. R.; Singh, D. J.; Fiolhais, C., Atoms, Molecules, Solids, and Surfaces - Applications of the Generalized Gradient Approximation for Exchange and Correlation. Phys. Rev. B 1992, 46 (11), 6671-6687. 
27. Bohlmark, J.; Lattemann, M.; Gudmundsson, J. T.; Ehiasarian, A. P.; Gonzalvo, Y. A.; Brenning, N.; Helmersson, U., The Ion Energy Distributions and Ion Flux Composition from a High Power Impulse Magnetron Sputtering Discharge. Thin Solid Films 2006, 515 (4), 1522-1526.

28. Briggs, D.; Grant, J. T., Surface Analysis by Auger and X-ray Photoelectron Spectroscopy. D. Briggs and J. T. Grant, Eds.; IMPublications, Chichester, UK and SurfaceSpectra, Manchester, UK, 2003; p 1-899.

29. Rosakis, A. J.; Singh, R. P.; Tsuji, Y.; Kolawa, E.; Moore Jr, N. R., Full Field Measurements of Curvature using Coherent Gradient Sensing: Application to Thin Film Characterization. Thin Solid Films 1998, 325 (1-2), 42-54.

30. Janssen, G. C. A. M.; Abdalla, M. M.; van Keulen, F.; Pujada, B. R.; van Venrooy, B., Celebrating the $100^{\text {th }}$ Anniversary of the Stoney Equation for Film Stress: Developments from Polycrystalline Steel Strips to Single Crystal Silicon Wafers. Thin Solid Films 2009, 517 (6), 1858-1867.

31. Oliver, W. C.; Pharr, G. M., An Improved Technique for Determining Hardness and Elastic Modulus using Load and Displacement Sensing Indentation Experiments. J. Mater. Res. 1992, 7 (06), 1564-1583.

32. Chase Jr, M. W., National Institute of Standards and Technology (U.S.), NIST-JANAF Thermochemical Tables. 4th ed.; American Chemical Society ; Woodbury, N.Y. : American Institute of Physics for the National Institute of Standards and Technology: Washington, D.C., USA, 1998; Vol. 2, p 1-1951.

33. Baragiola, R. A.; Alonso, E. V.; Ferron, J.; Oliva-Florio, A., Ion-Induced Electron Emission from Clean Metals. Surf. Sci. 1979, 90 (2), 240-255. 
34. Allen, F. G.; Gobeli, G. W., Work Function, Photoelectric Threshold, and Surface States of Atomically Clean Silicon. Phys. Rev. 1962, 127 (1), 150-158.

35. Allen, F. I.; Persaud, A.; Park, S. J.; Minor, A.; Sakurai, M.; Schneider, D. H.; Schenkel, T., Transport of Multiply and Highly Charged Ions through Nanoscale Apertures in Silicon Nitride Membranes. Nucl. Instrum. Methods Phys. Res., Sect. B 2006, 244 (2), 323-326.

36. Depla, D.; Colpaert, A.; Eufinger, K.; Segers, A.; Haemers, J.; De Gryse, R., Target Voltage Behaviour during DC Sputtering of Silicon in an Argon/Nitrogen Mixture. Vacuum 2002, 66 (1), 9-17.

37. Schmidt, S.; Czigany, Z.; Greczynski, G.; Jensen, J.; Hultman, L., Ion Mass Spectrometry Investigations of the Discharge during Reactive High Power Pulsed and Direct Current Magnetron Sputtering of Carbon in Ar and Ar/ $\mathrm{N}_{2}$. J. Appl. Phys. 2012, 112 (1), 013305-11.

38. Ehiasarian, A. P.; Vetushka, A.; Hecimovic, A.; Konstantinidis, S., Ion Composition Produced by High Power Impulse Magnetron Sputtering Discharges Near the Substrate. J. Appl. Phys. 2008, 104 (8), 8.

39. Itikawa, Y., Cross Sections for Electron Collisions with Nitrogen Molecules. J. Phys. Chem. Ref. Data 2006, 35 (1), 31-53.

40. Bibinov, N. K.; Kokh, D. B.; Kolokolov, N. B.; Kostenko, V. A.; Meyer, D.; Vinogradov, I. P.; Wiesemann, K., A Comparative Study of the Electron Distribution Function in the Positive Columns in $\mathrm{N}_{2}$ and $\mathrm{N}_{2} / \mathrm{He}$ DC Glow Discharges by Optical Spectroscopy and Probes. Plasma Sources Sci. Technol. 1998, 7 (3), 298-309. 
41. Kimura, T.; Kasugai, H., Experiments and Global Model of Inductively Coupled RF Ar/ $\mathrm{N}_{2}$ Discharges. J. Appl. Phys. 2010, 108 (3), 033305.

42. Hierl, P. M.; Franklin, J. L., Appearance Potentials and Kinetic Energies of Ions from $\mathrm{N}_{2}$, CO, and NO. J. Chem. Phys 1967, 47 (9), 3154-3161.

43. Hala, M.; Viau, N.; Zabeida, O.; Klemberg-Sapieha, J. E.; Martinu, L., Dynamics of Reactive HighPower Impulse Magnetron Sputtering Discharge studied by Time- And Space-Resolved Optical Emission Spectroscopy and Fast Imaging. J. Appl. Phys. 2010, 107 (4), 9.

44. Lempérière, G.; Poitevin, J. M., The Influence of $\mathrm{N}_{2}$ Partial Pressure and Substrate Bias on Electron Density and Temperature in a dc Sputtering Diode. Vacuum 1987, 37 (11-12), 825-830.

45. Takaki, K.; Chang, J.; x; Shih; Kostov, K. G., Atmospheric Pressure of Nitrogen Plasmas in a Ferroelectric Packed Bed Barrier Discharge Reactor. Part I. Modeling. IEEE Trans. Dielectr. Electr. Insul. 2004, 11 (3), 481-490.

46. Delmotte, F.; Hugon, M. C.; Agius, B.; Pointu, A. M.; Teodoru, S., Langmuir Probe Analysis of Distributed Electron Cyclotron Resonance Silicon Nitride Deposition Plasma. Appl. Phys. Lett. 1998, 72 (12), 1448-1450.

47. Kraft, R.; Schneider, T. P.; Dostalik, W. W.; Hattangady, S., Surface Nitridation of Silicon Dioxide with a High Density Nitrogen Plasma. J. Vac. Sci. Technol., B: Nanotechnol. Microelectron.: Mater., Process., Meas., Phenom. 1997, 15 (4), 967-970.

48. Greczynski, G.; Hultman, L., Time and Energy Resolved Ion Mass Spectroscopy Studies of the Ion Flux during High Power Pulsed Magnetron Sputtering of $\mathrm{Cr}$ in $\mathrm{Ar}$ and $\mathrm{Ar} / \mathrm{N}_{2}$ Atmospheres. Vacuum 2010, 84 (9), 1159-1170. 
49. Hollands, E.; Campbell, D. S., The Mechanism of Reactive Sputtering. J. Mater. Sci. 1968, 3 (5), 544-552.

50. Kärcher, R.; Ley, L.; Johnson, R. L., Electronic Structure of Hydrogenated and Unhydrogenated Amorphous $\operatorname{SiN}_{\mathrm{x}}(0 \leq \mathrm{x} \leq 1.6)$ : A Photoemission Study. Phys. Rev. B 1984, 30 (4), 1896-1910.

51. Burkhardt, P. J.; Marvel, R. F., Thermal Expansion of Sputtered Silicon Nitride Films. J. Electrochem. Soc. 1969, 116 (6), 864-866.

52. Nir, D., Intrinsic Stress in Diamond-Like Carbon Films and its Dependence on Deposition Parameters. Thin Solid Films 1987, 146 (1), 27-43.

53. Wang, H. L.; Lin, C. H.; Hon, M. H., The Dependence of Hardness on the Density of Amorphous Alumina Thin Films by PECVD. Thin Solid Films 1997, 310 (1-2), 260-264.

54. Huang, H.; Winchester, K. J.; Suvorova, A.; Lawn, B. R.; Liu, Y.; Hu, X. Z.; Dell, J. M.; Faraone, L., Effect of Deposition Conditions on Mechanical Properties of Low-temperature PECVD Silicon Nitride Films. Mater. Sci. Eng., A 2006, 435-436, 453-459.

55. Ziegler, J. F. SRIM - The Stopping and Range of Ions in Matter and TRIM - Transport of Ions in Matter, http://www.srim.org/, 2008.

56. Hammer, P.; Alvarez, F., Influence of Chemical Sputtering on the Composition and Bonding Structure of Carbon Nitride Films. Thin Solid Films 2001, 398-399, 116-123.

57. Jacob, W.; Hopf, C.; Schluter, M., Chemical Sputtering of Carbon by Nitrogen Ions. Appl. Phys. Lett. 2005, 86 (20), 204103. 


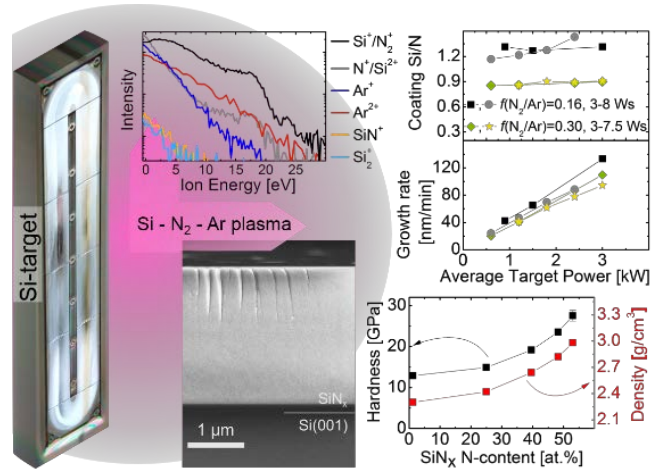

TOC 